\title{
POLUIÇÃO ATMOSFÉRICA, PROBLEMAS RESPIRATÓRIOS E CARDIOVASCULARES: INVESTIGANDO O SETOR FERROLIGAS EM PIRAPORA/MG, BRASIL
}

\author{
Gustavo Lino Mendonça \\ Serviço Autônomo de Água e Esgoto de Buritizeiro/MG - SAAE \\ Buritizeiro, MG, Brasil \\ gustavolino1886@yahoo.com.br \\ Sandra Célia Muniz Magalhães \\ Universidade Estadual de Montes Claros - UNIMONTES \\ Departamento de Geociências, Montes Claros, MG, Brasil \\ sandramunizgeo@hotmail.com \\ Cássio Alexandre da Silva \\ Universidade Estadual de Montes Claros - UNIMONTES \\ Departamento de Geociências, Montes Claros, MG, Brasil \\ cassioas27@gmail.com
}

\section{RESUMO}

A poluição atmosférica industrial tem sido objeto de pesquisas que vem confirmando a correlação entre o aumento da poluição do ar com manifestações de Doenças e Agravos DeA respiratórios e cardiovasculares. O objetivo geral do estudo foi discutir sobre os efeitos das emissões de poluentes atmosféricos oriundos de empreendimentos do Setor Ferroligas que operam em Pirapora/MG/Brasil, sobre a saúde da população vizinha a esses empreendimentos. A metodologia consistiu na realização de um estudo ecológico que contemplou pesquisa bibliográfica, pesquisa de gabinete e levantamentos de campo. Após a obtenção de uma Área de Risco Ambiental para poluentes atmosféricos - ARA, foram selecionados dois Territórios de Saúde - TS. O primeiro (Vila Maria), sobreposto pela ARA e o segundo (Novo Buritizeiro), externo à ARA. Foram levantados dados primários dos diagnósticos de DeA respiratórios e cardiovasculares desses mesmos TS, para fins de confrontamento e análise das taxas. O TS Vila Maria apresentou taxas de diagnósticos superiores ao TS Novo Buritizeiro de 53,38\% (2015) e 89,62\% (2016) e em média, 70,53\%. Concluiu-se que as emissões de poluentes atmosféricos das indústrias pesquisadas colaboraram significativamente para o aumento de DeA respiratórios e cardiovasculares na população do entorno e que crianças e idosos foram os mais afetados.

Palavras-Chave: Material particulado. Doenças e agravos. Metalúrgicas. Pirapora/MG.

\section{ATMOSPHERIC POLLUTION, RESPIRATORY AND CARDIOVASCULAR PROBLEMS: INVESTIGATING THE FERROALLOYS SECTOR IN PIRAPORA / MG, BRAZIL}

\begin{abstract}
Industrial air pollution has been object of researches which have confirmed connection between the increase of air pollution and manifestations of respiratory and cardiovascular Diseases and Aggravation - DA. General purpose of the study was to discuss the effects of atmospheric pollutants emissions from the Ferroalloys Sector projects operating in Pirapora/MG/Brazil, on the health of population neighboring these enterprises. Methodology consisted in the execution of an ecological study contemplating bibliographical research, cabinet research and field surveys. After obtaining an Environmental Risk Area for air pollutants - ERA, two Health Territories - HT were selected. The first (Vila Maria), overlaid by ERA and the second (Novo Buritizeiro), external to ERA. Primary data from the respiratory and cardiovascular DA diagnoses of these same TS, collected for comparison and rate analysis purposes. HT Vila Maria presented diagnostic rates higher than HT Novo Buritizeiro of $53.38 \%(2015)$ and $89.62 \%(2016)$, and on average, $70.53 \%$. It was concluded that the emissions of air pollutants from the industries surveyed contributed significantly to the increase in respiratory and cardiovascular diseases DA in the surrounding population, also that children and elderly were the most affected.
\end{abstract}

Keywords: Particulate matter. Diseases and Aggravation. Metallurgies. Pirapora/MG.

$\begin{array}{llllll}\text { Caminhos de Geografia } & \text { Uberlândia-MG } & \text { v. 20, n. } 70 \quad \text { Junho/2019 } & \text { p. 398-417 } & \text { Página } 398\end{array}$




\section{INTRODUÇÃO}

Poluição atmosférica ocorre quando emissões de substâncias são lançadas no ar em concentrações capazes de causar danos em seres humanos, animais, vegetais ou mesmo em materiais (BRAGA, et al., 2010 p.170). Quando a origem da poluição provém de atividades industriais é designada poluição industrial.

A poluição atmosférica industrial tem sido objeto de pesquisas que comumente se corroboram quanto aos efeitos deletérios na saúde de populações expostas a ambientes cujos limites máximos de um ou mais poluentes são excedidos. Além de trabalhos no meio acadêmico, a preocupação da sociedade para com a degradação da qualidade do ar tem sido manifestada por meio de políticas públicas que buscam, via instrumentos diversos (licenciamento ambiental, redes de monitoramento da qualidade do ar, estabelecimento de limites de emissões), uma atmosfera saudável em capitais, regiões metropolitanas e industriais. Essas políticas (e pesquisas) estão presentes em várias partes do Mundo e no Brasil, mas menos efetivas em escala local, o que pode colaborar para a exposição de populações que vivem no interior, seja pela falta de bases argumentativas verificáveis, seja pela ausência ou fragilidade dos sistemas de monitoramento e controle da poluição.

Muitos estudos, nacionais e internacionais (alguns dos quais citados no presente artigo), foram realizados com uma abordagem comparativa entre internações hospitalares e mortalidades associadas a níveis de monitoramento da qualidade do ar, geralmente utilizando-se de dados secundários. Por outro lado, são escassas as pesquisas cuja metodologia focou na produção de dados primários de morbidades quando obtidos diretamente na atenção primária à saúde e tendo como outro parâmetro comparativo, a abordagem espacial, como forma de distinção de níveis de exposição da população ao poluente estudado.

Pirapora está localizada na região Norte do Estado de Minas Gerais, Brasil, à margem direita do Rio São Francisco. Abriga um distrito industrial com significativas emissões de poluentes atmosféricos oriundos principalmente das chaminés das metalúrgicas do Setor produtor de ferroligas e ligas não metálicas, com predominância de emissões do poluente Material Particulado - MP. Na margem oposta do citado Rio encontra-se a cidade de Buritizeiro/MG, também sob influência desses poluentes.

Essas metalúrgicas, em operação no local há mais de três décadas, passaram por processos de regularização ambiental, mas a obtenção de certificados de licença não significa, necessariamente, que as fontes de poluição estejam sob controle e que a população vizinha a esses empreendimentos esteja em segurança. Até dezembro de 2016 quatro dos quatorze fornos com histórico de operação não tinham recebido sistemas de despoeiramento (filtros), lançando toneladas de gases $\mathrm{e}$ particulados na atmosfera respirada por dezenas de milhares de pessoas. Esses lançamentos, quando em limites acima dos permitidos em lei, ameaçam a saúde das pessoas e o meio ambiente local:

[...] quando os padrões de qualidade do ar são ultrapassados, a saúde, a segurança e o bem estar da população podem ser afetados e, além disso, podem ser ocasionados danos à flora, à fauna, aos materiais e ao meio ambiente em geral. Assim, as emissões do material particulado provenientes dos fornos das empresas [...] ocasionam o uso abusivo do recurso natural ar atmosférico, bem como a degradação de sua qualidade, comprometendo o direito da população local de respirar um ar mais saudável (DINIZ, 2011, p. 17).

Trabalhamos com a hipótese de que a população urbana dos municípios supracitados esteve por décadas e ainda está exposta aos riscos de uma atmosfera degradada pela emissão de poluentes atmosféricos, principalmente Material Particulado, gerado nas metalúrgicas produtoras de ferroligas, que operam no Distrito Industrial de Pirapora/MG. Para confirmar ou refutar tal hipótese, foi realizado um estudo ecológico que, em suma, avaliou dois grupos distintos (controle e resposta) quanto ao nível de exposição aos poluentes, sendo o ser humano o bioindicador de referência.

\section{METODOLOGIA}

Para subsidiar o estudo geográfico e epidemiológico proposto, tornou-se imperativo a sustentação teórica. Esta foi dividida em dois subtópicos: o primeiro caracterizando os poluentes passíveis de

\begin{tabular}{llllll}
\hline Caminhos de Geografia & Uberlândia-MG & v. 20, n. 70 & Junho/2019 & p. 398-417 & Página 399
\end{tabular}


Poluição atmosférica, problemas respiratórios e cardiovasculares: investigando o setor ferroligas em Pirapora/MG, Brasil
Gustavo Lino Mendonça Sandra Célia Muniz Magalhães Cássio Alexandre da Silva

colaborarem com os resultados alcançados, caracterização esta quanto à composição, forma das partículas e histórico da quantidade gerada. Foram consultados Dellamano (2005), MINAS GERAIS (2010), Diniz (2011) e Ribeiro (2016).

O segundo subtópico abordou o comportamento da pluma de poluição sendo o aporte fundamental obtido nos trabalhos de Ribeiro et al. (2014) e Ribeiro (2016). Foram abordados ainda os efeitos sobre a saúde nas populações humanas expostas a estes poluentes, em especial para os relacionados a problemas respiratórios e cardiovasculares, com base nos trabalhos de Braga et al. (2007), Olmo (2011), WHO (2017), Lipfert (2017), Silveira e Junger (2018), Schraufnagel et al., (2018), Hamanaka e Mutlu (2018), Casio e Long (2018), Nhung et al. (2018), Nardocci et al.(2013). Os parâmetros de monitoramento do poluente Material Particulado com diâmetro inferior a 10 micrômetros $\left(\mathrm{PM}_{10}\right)$ foram obtidos com Liasa (2014), que é uma das três empresas com histórico de emissões significativas de poluentes atmosféricos (especialmente $\mathrm{PM}_{10}$ ) no recorte pesquisado. Os resultados foram confrontados com os parâmetros para definição da qualidade do ar divulgados pela Companhia Ambiental do Estado de São Paulo - CETESB (SÃO PAULO, 2017) e limites estabelecidos pelo Conselho Nacional do Meio Ambiente - CONAMA (BRASIL, 1990).

A consulta documental foi uma etapa fundamental para o alcance dos objetivos. A principal fonte dos dados das metalúrgicas de Pirapora foram os processos de regularização ambiental, obtidos através de pedido de vistas junto à Superintendência de Regularização Ambiental do Norte de Minas SUPRAN-NM, em 27 de março de 2017 e via rede mundial de computadores, Portal do Sistema Estadual de Informações Ambientais do Estado de Minas Gerais - SIAM/MG.

Para a obtenção dos resultados foram confrontadas as variáveis: taxas e índices populacionais de doenças e agravos respiratórios e cardiovasculares versus localização de dois territórios de saúde sendo que, um deles, inserido na área de maior risco ambiental para poluentes atmosféricos (Figura 1 - A) e o outro, fora (Figura 1 - B):

Figura 1 - Distribuição espacial dos Territórios de Saúde pesquisados em relação à ARA e entre si.

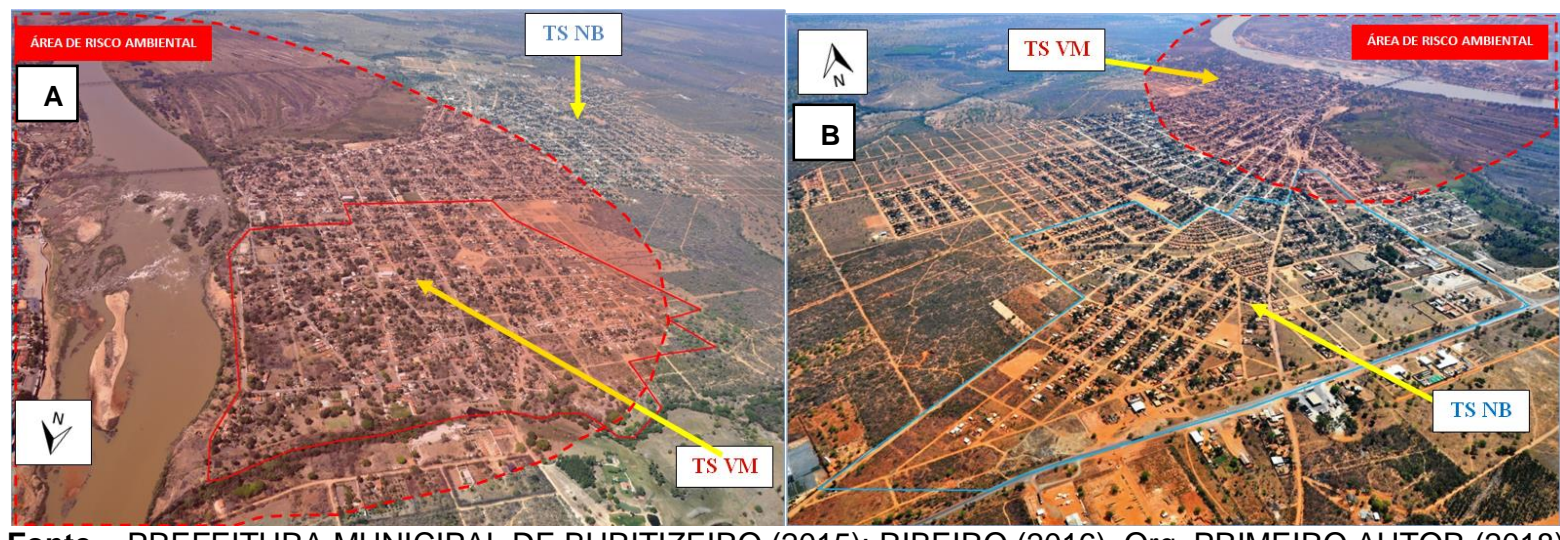

Fonte - PREFEITURA MUNICIPAL DE BURITIZEIRO (2015); RIBEIRO (2016). Org. PRIMEIRO AUTOR (2018)

Para a seleção dos recortes espaciais amostrados foi considerado o estudo de Ribeiro (2016), que determinou a Área de maior Risco Ambiental - ARA para poluentes atmosféricos. Nas imagens aéreas acima, a mesma encontra-se destacada com um polígono preenchido com tonalidade em vermelho, efeito de transparência e bordas pontilhadas. A ARA engloba praticamente toda a cidade de Pirapora e seus Territórios de Saúde - TS, este definido como a área de abrangência de cada unidade básica de saúde (MONKEN e BARCELLOS, 20--).

Foi selecionada em Buritizeiro uma área contígua, não sobreposta pela referida área de risco, espaço que abarca os limites do Território de Saúde Novo Buritizeiro (polígono azul da Figura 1-B), identificado nos levantamento de campo como o único com uma coleção de arquivos acessíveis e passível de confrontamento com os resultados do Território de Saúde Vila Maria (polígono em vermelho, borda contínua, Figura 1-A).

A Figura 2 ilustra a localização dos espaços e das entidades objeto da análise (cidades, territórios de saúde, indústrias e Área de Risco Ambiental - ARA).

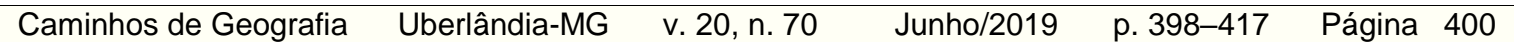


Figura 2 - Distribuição espacial das entidades envolvidas na análise espacial dos fenômenos estudados.

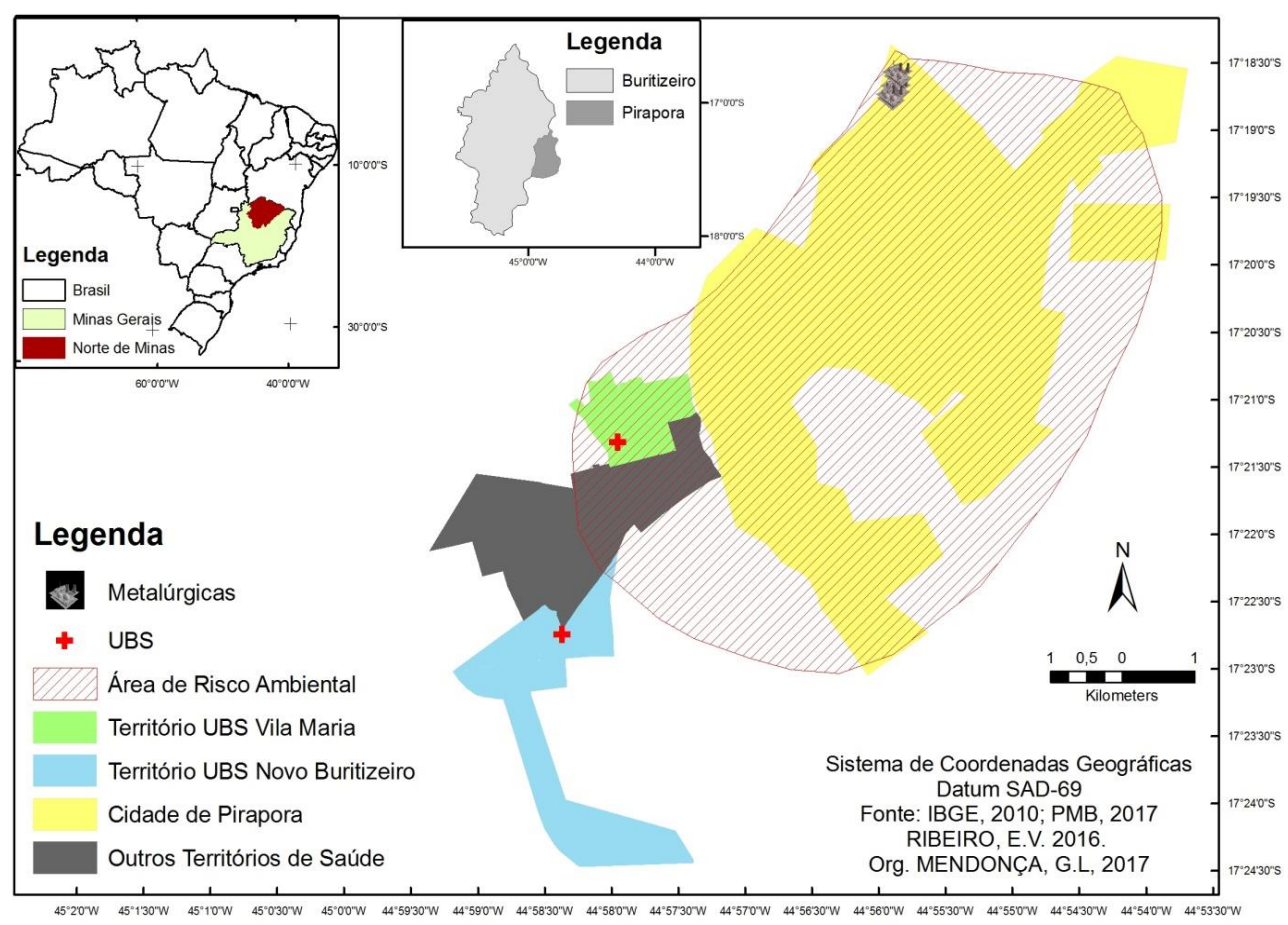

Fonte - Elaborado por PRIMEIRO AUTOR (2017).

O método utilizado foi o indutivo, com aplicação da observação dos fenômenos que envolvem: a poluição atmosférica gerada nas metalúrgicas; os registros de diagnósticos de doenças e agravos respiratórios e cardiovasculares em dois Territórios de Saúde opostos no quesito susceptibilidade à circulação/deposição de particulados das fontes fixas estudadas; a comparação dos resultados obtidos e finalmente, generalização das conclusões para os demais territórios dos distritos sedes das cidades de Buritizeiro e Pirapora.

Quanto ao alinhamento do trabalho com a epidemiologia, optou-se pelo estudo ecológico:

Os estudos ecológicos são voltados a grupos populacionais utilizando índices ou taxas de mortalidade e morbidade, variáveis ambientais, culturais, socioeconômicas. É considerado por muitos autores como um estudo analítico. Em Saúde Ambiental geralmente comparam-se registros temporais de dados de exposição com os de efeitos adversos. (FUNASA, 2002, p.89).

Dados primários foram coletados e com base nos mesmos, criados índices e taxas para dois grupos populacionais: um que vive em uma área mais afetada pela poluição atmosférica e outro, que vive em um ambiente menos afetado que o primeiro, ou seja, variáveis ambientais. Então, foram verificados efeitos adversos na população, com base em registros temporais. Segundo a Funasa (2002, p. 89): "[...] as características desse estudo são as seguintes: levantar hipóteses (podendo testá-las); utilizar variáveis agrupadas (perspectiva integralizadora); relacionar o grupo populacional com as variáveis em estudo; realizar uma abordagem geográfica".

Vários estudos longitudinais, ecológicos e epidemiológicos confirmaram a correlação entre níveis externos de poluentes atmosféricos e os efeitos adversos sobre a saúde humana, em especial quando associados a internações hospitalares motivadas por problemas respiratórios e cardiovasculares (CRUZ et al., 2015).

Estudos ecológicos usando séries temporais ou análises estratificadas no tempo, objetivando estimar os efeitos a curto prazo no aparelho respiratório encontraram associações positivas entre aumentos diários na poluição do ar e aumentos diários na morbidade e mortalidade por doenças respiratórias (SZYSZKOWICZ, M., ET AL.,2018, p.264).

Silveira e Junger (2018) lançaram mão do estudo ecológico ao investigarem a associação entre espaços verdes e a mortalidade por doenças isquêmicas do coração e cerebrovasculares, introduzindo a variável socioeconômica nessa relação. Os autores concluíram, em suma, que na cidade do Rio de Janeiro as taxas de mortalidade por esses tipos de doenças são inversamente associadas à exposição aos espaços verdes.

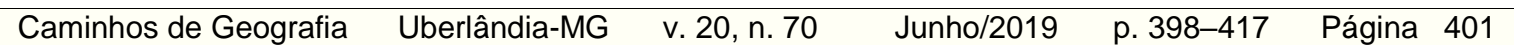


A hipótese formulada foi a de que a população das cidades de Buritizeiro e Pirapora estiveram sob a influência da poluição atmosférica e que essa condição causa efeitos adversos na saúde das pessoas. Tal possibilidade foi testada por meio de dois grupos populacionais submetidos à variável poluição atmosférica, via abordagem geográfica.

Para verificar o grau de morbidade, isto é, a quantidade de pessoas doentes ou que adoeceram nos territórios pesquisados, no período em questão, foram considerados as doenças e agravos respiratórios e cardiovasculares segundo os diagnósticos médicos (consultas médicas) lançados nas Fichas de Atendimento Individual, modelo padrão do Ministério da Saúde, versão e-SUS, fichas estas arquivadas nas respectivas Unidades Básicas de Saúde. Nas referidas fichas, há campos específicos para a inserção da Classificação Estatística Internacional de Doenças e Problemas Relacionados à Saúde, mais conhecida como CID-10, que é um catálogo internacional que permite que os profissionais de saúde compartilhem informações de saúde em nível global, atualizada recentemente para CID-11(OPAS, 2018). Essas mesmas fichas possuem ainda, como segunda opção de lançamento ao profissional que efetuou a consulta, o campo CIAP-2, que é o Sistema Internacional de Classificação Primária, Segunda Edição. Este considera, além do problema de saúde, os motivos da consulta e as respostas propostas pela equipe da Estratégia da Saúde da Família. A CIAP sempre esteve ligada a CID (SBMFC, 2009).

A maioria dos diagnósticos lançados estavam classificados com a CID-10 apesar de haver lançamentos de CIAP-2, fato que não prejudicou os levantamentos, há codificações correspondentes entre os sistemas. Enquanto que na CID-10 os diagnósticos de doenças do aparelho respiratório estão abarcados entre o intervalo J00-J99 e os do aparelho circulatório estão entre 100-199, no CIAP2 os correspondentes estão entre R01-R99 e K01-K99, respectivamente, por grupo de enfermidades/diagnósticos.

Ao se trabalhar com a CID-10 exclui-se grupos de patologias que, vias de regra, não estão associadas à morbidade provocada ou agravada pela poluição do ar. A CID-10, codificações J00-J99 e 100-199, excluem morbidades de origem parasitária, afecções originadas no período perinatal, complicações na gravidez, parto e puerpério, doenças endócrinas, nutricionais e metabólicas, lesões traumáticas, intoxicações e outras consequências de causas externas, transtornos sistêmicos do tecido conjuntivo, sintomas, sinais e achados clínicos e laboratoriais anormais, não classificados em outra parte (MINISTÉRIO DA SAÚDE, 2019). A CID-10 oferece esta e outras vantagens, algumas exploradas por Qu Y., et al. (2018, p. 2-3). Os autores obtiveram números de mortes não acidentais (CID-10 A00 e R99) e de doenças do sistema circulatório (CID-10 100-199) e dessa forma determinaram o número de mortes não acidentais diárias por problemas do sistema circulatório, o que permitiu a comparação com registros de monitoramento do poluente $\mathrm{PM}_{2,5}$ e dados meteorológicos. O artigo $1^{\circ}$ da Portaria 104 do Ministério da Saúde conceitua doença como: "I - [...] uma enfermidade ou estado clínico, independentemente de origem ou fonte, que represente ou possa representar um dano significativo para os seres humanos" ao passo que agravo: "II - significa qualquer dano à integridade física, mental e social dos indivíduos provocado por circunstâncias nocivas, como acidentes, intoxicação, abuso de drogas, e lesões auto ou heteroinfligidas" (MINISTÉRIO DA SAÚDE, 2011).

Com os Agentes Comunitários de Saúde - ACS (que basearam-se nas anotações em seus Cadernos de Acompanhamento Domiciliar) foram obtidas as informações demográficas: número de pessoas e o número de residências atendidas, por microárea de saúde, conforme exposto na Figura 3:

Figura 3 - Número de residências e pessoas, por TS e total, em 2017.

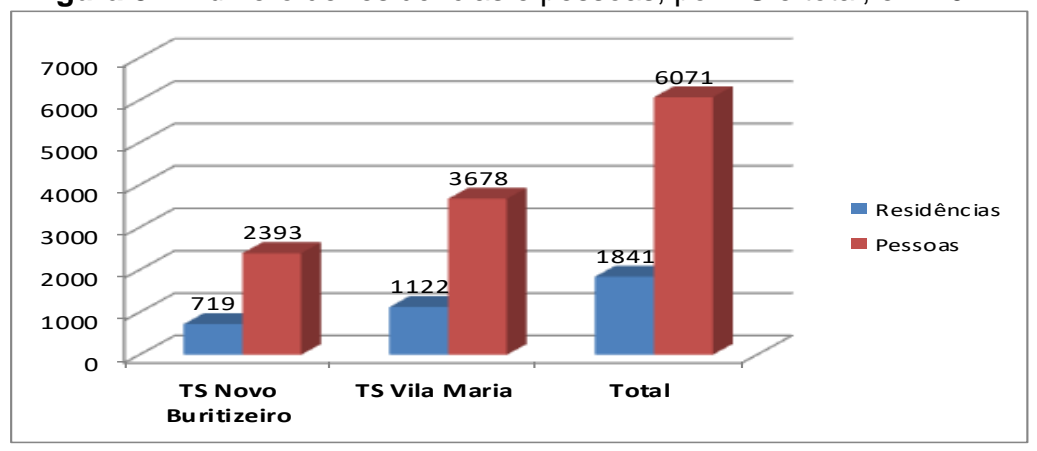

Fonte - Pesquisa direta (2017).

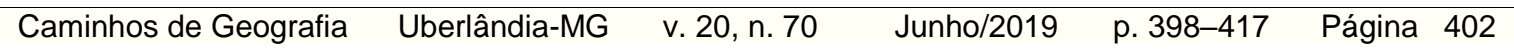


Os dados informados pelas ACS tiveram como referência temporal o momento das checagens em seus respectivos Cadernos de Acompanhamento Domiciliar. Não foram encontrados nos arquivos das Unidades Básicas de Saúde todos os cadernos utilizados nos anos de 2015 e 2016, razão da opção pelos cadernos de 2017. Apesar disso, no período (2015 a 2017) não ocorreu nenhum evento que acelerasse a dinâmica populacional dos territórios de saúde pesquisados (emigração, imigração, natalidade, mortalidade, epidemias, endemias, etc.). Tal condição somada ao tamanho das amostras permite o desprezo de pequenas variações.

Dessa forma foi obtido o número de pessoas, por Território de Saúde, para compor a fórmula matemática (1) que gerou um Índice de Morbidade Populacional Geral - IMP-G, dividindo-se a população do território pelo número total de diagnósticos CID-10 I e J (ou CIAP-2 R e K):

IMP-G $=p / d$

Em que (IMP-G) é o Índice de Morbidade Populacional Geral, (p) é população total do território e (d) representa o número total de diagnósticos de doenças e agravos, no período.

Além do citado índice, que considera toda a população por TS, foi criada a Taxa de Morbidade Populacional Geral - TMP-G, que nada mais é do que o percentual de doenças e agravos I e J diagnosticados em relação ao número total de consultas, por TS.

A fórmula (2) que representa o raciocínio é a seguinte:

TMP-G $=d^{*} 100 / c$

Em que (TMP-G) é a Taxa de Morbidade Populacional Geral, (d) é o número total de diagnósticos de doenças e agravos, no período e (c), o número total de consultas realizadas no período.

No momento do lançamento dos dados foi procedida a distribuição dos diagnósticos por faixas etárias, o que viabilizou o trabalho com taxas de morbidade para jovens e crianças (igual ou menor que 19 anos de idade), idosos (igual ou maior que 64 anos de idade) e os de idade intermediária (outros). Não foram considerados os meses e dias de nascimento. A opção pela delimitação em estratos etários foi motivada pelos resultados de diversos estudos que apontam para tendências de diferenciação quali-quantitavivas na morbidade e mortalidade de populações expostas a poluentes atmosféricos, com destaque para a exposição ao poluente Material Particulado.

Nhung et al., (2018, p.139) chamam a atenção para o fato de que o sistema respiratório de crianças é mais susceptível aos efeitos adversos da poluição do ar. Elas possuem taxas de respiração mais elevadas que os adultos além de tenderem a passar mais tempo ao ar livre praticando atividades físicas e consequentemente, inalando doses mais altas de poluentes atmosféricos. Du et al., (2016, p. E-14) concluíram que as evidencias da relação entre poluição por material particulado e doenças do aparelho circulatório são inequívocas e que mesmo exposições de curto prazo podem desencadear mortalidades e morbidades cardiovasculares, especialmente em indivíduos pertencentes a grupos de risco, como idosos e pacientes com doença arterial coronariana preexistente. Já Qu et al., (2018, p.01) descobriram que a exposição a curto prazo ao poluente $\mathrm{PM}_{2,5}$ aumentou o risco de mortalidade por doenças não acidentais do aparelho circulatório em idosos de Changchun, capital da província de Jilin, China.

Quanto ao tamanho e distribuição da amostra, a mesma pode ser visualizada na Figura 4:

Figura 4 - Distribuição espacial e temporal do universo amostral.

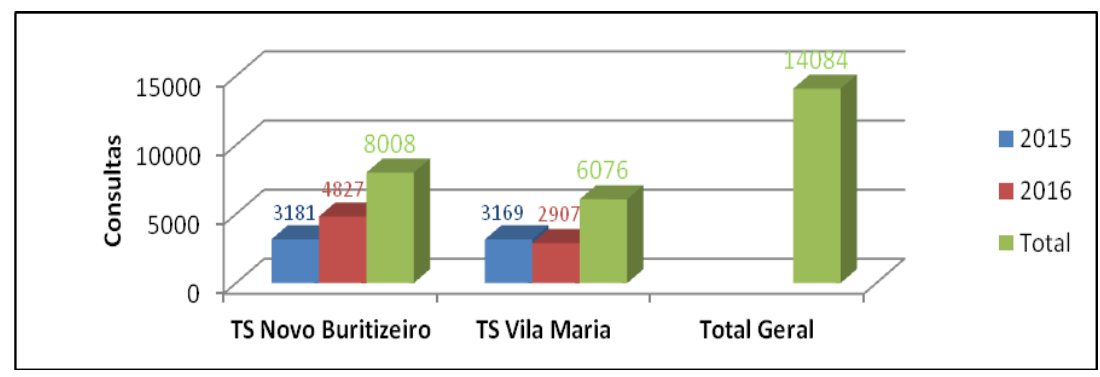

Fonte - Pesquisa direta.

$\begin{array}{llllll}\text { Caminhos de Geografia } & \text { Uberlândia-MG } & \text { v. 20, n. } 70 & \text { Junho/2019 } & \text { p. 398-417 Página } 403\end{array}$


A abrangência foi a totalidade das consultas realizadas na população dos Territórios de Saúde entre os anos de 2015 e 2016 sendo: para a Unidade Básica de Saúde Vila Maria 3.169 e 2.907, respectivamente. Para a Unidade Básica de Saúde Novo Buritizeiro, 3.181 e 4.827, na mesma ordem. Portanto, foi amostrado para 2015, 6.350 consultas e para 2016, 7.734, totalizando 14.084 diagnósticos.

\section{CARACTERIZAÇÃO dOS POLUENTES ATMOSFÉRICOS DAS METALÚRGICAS DE PIRAPORA/MG}

Os principais poluentes atmosféricos gerados na produção de ferroligas e silício metálico são constituídos de: MP (Material Particulado) e gases como SO²(Dióxido de Enxofre) NOx (Óxidos de Nitrogênio), $\mathrm{CO}$ (Monóxido de Carbono), $\mathrm{CO}^{2}$ (Dióxido de Carbono), hidrocarbonetos aromáticos policíclicos. São produzidos ainda metais pesados, dependendo do tipo de metal produzido, da idade da planta e do tipo de tecnologia (MINAS GERAIS, 2010, p.14). Quanto ao MP, o mesmo é composto principalmente por microssílica (sílica ativa) e em menor quantidade, por partículas de carbono. Para cada tonelada de ferro silício 75 produzido é gerado aproximadamente $350 \mathrm{Kg}$ de microssílica, ao passo que a produção da mesma quantidade de silício metálico gera aproximadamente $550 \mathrm{~kg}$ do mesmo material (DELLAMANO, 1995, p.30).

Ribeiro (2016, p. 20) analisou a poluição atmosférica causada pelas indústrias produtoras de ferro silício e silício metálico que operam em Pirapora a partir da caracterização mineralógica, morfológica e química do material particulado emitido pelas mesmas. A pesquisa estendeu-se com a identificação e a distribuição espacial dessas partículas. A autora constatou, além de sílica, a presença dos metais Zinco (Zn), Cobre (Cu), Chumbo (Pb), Cromo (Cr) e Níquel (Ni):

[...] composição principal de sílica $(95,52 \%)$ de fase amorfa e concentrações de metais como $\mathrm{Zn}(74,6 \mathrm{ppm}), \mathrm{Cu}(28,8 \mathrm{ppm}), \mathrm{Pb}(19 \mathrm{ppm}), \mathrm{Cr}(33,3 \mathrm{ppm})$ e $\mathrm{Ni}(7$ $\mathrm{ppm})$. A faixa de tamanho varia entre 0,18 e $123 \mu \mathrm{m}$, das quais $95 \%$ são partículas menores que $50 \mu \mathrm{m}$, as Partículas Totais em Suspensão (PTS). O material de maior risco inclui $30 \%$ do material particulado, são as partículas inaláveis menor que $10 \mu \mathrm{m}$. Compostos de carbono, de dimensões milimétricas, apresentaram maior ocorrência na área de emissão e nos pontos mais adjacentes ao distrito industrial $(1,8 \mathrm{Km})$ (RIBEIRO, 2016, p. 137).

Quanto à forma, a mesma autora identificou partículas esféricas, cuja composição contém Silício (Si), Ferro ( $\mathrm{Fe}$ ), Bário (Ba), Tálio ( $\mathrm{Ti})$ e Cromo ( $\mathrm{Cr}$ ), foram identificadas em todas as amostras, chegando até a distância máxima monitorada por Ribeiro, que foi de 21,7Km (Figuras $5 \mathrm{~A}$ e 5B):

Figura 5 - Amostras da cidade de Buritizeiro (A) e partículas de carbono com silício (B).

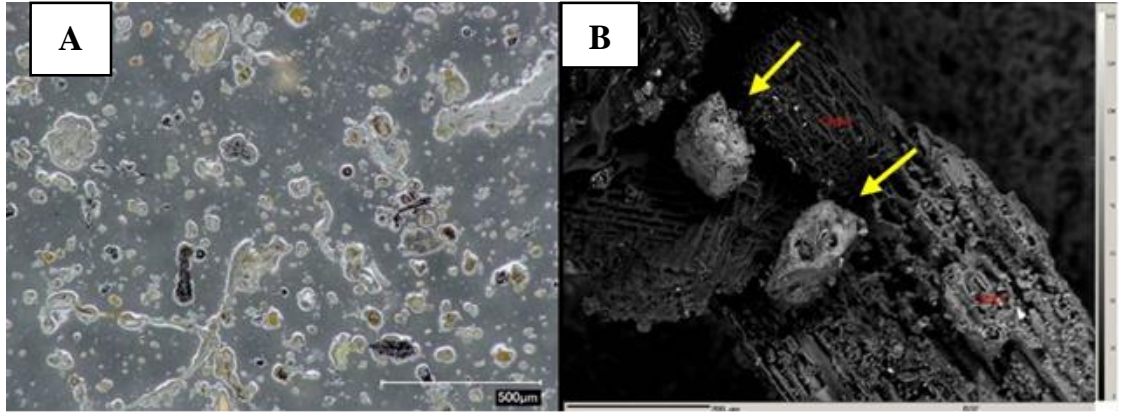

Fonte - Adaptado de RIBEIRO (2016, p. 118-119).

O material particulado apresentado na Figura $5 \mathrm{~A}$ foi colhido na área urbana de Buritizeiro, a $6,5 \mathrm{Km}$ de distância das fontes de emissão. A microfotografia da Figura 5B capturou a imagem de uma partícula de carbono e sobre a mesma, de menor tamanho e coloração mais clara (setas amarelas), partículas de silício. Ambas as amostras (e micrografias) fazem parte da Tese de Ribeiro (2016), onde os detalhes acerca da metodologia utilizada pela autora podem ser consultados.

$\begin{array}{llllll}\text { Caminhos de Geografia } & \text { Uberlândia-MG } & \text { v. 20, n. } 70 & \text { Junho/2019 } & \text { p. 398-417 } & \text { Página } 404\end{array}$


Passa-se agora a analisar a quantidade de MP emitido pelos empreendimentos pesquisados. A Tabela 1 informa que, no ano de 2011, ocorreu a emissão de 26.787 toneladas de MP na atmosfera onde respiram atualmente aproximadamente 74.399 pessoas (IBGE, 2010):

Tabela 1 - Taxa de emissão de MP por forno sem filtro em 2011.

\begin{tabular}{|c|c|c|}
\hline EMPRESA & FORNOS & $\begin{array}{l}\text { TAXA DE EMISSÃO } \\
\text { KG/H }\end{array}$ \\
\hline \multirow{3}{*}{ MINASLIGAS } & $\mathrm{F}-1$ & 255,00 \\
\hline & $\mathrm{F}-2$ & 255,00 \\
\hline & $\mathrm{F}-3$ & 255,00 \\
\hline \multirow{4}{*}{ LIASA } & $\mathrm{F}-1$ & 315,65 \\
\hline & $\mathrm{F}-2$ & 922,36 \\
\hline & $\mathrm{F}-3$ & 628,57 \\
\hline & $\mathrm{F}-4$ & 648,21 \\
\hline INONIBRÁS & $\mathrm{F}-1$ & 76,99 \\
\hline \multicolumn{2}{|c|}{ TOTAL EMISSÃO KG/HORA: } & $3.356,78$ \\
\hline \multicolumn{2}{|c|}{ TOTAL DE EMISSÃO T/ANO*: } & 26.787 t/ano \\
\hline
\end{tabular}

Nota - ${ }^{*}$ Considerando um funcionamento efetivo médio de cada forno de 7.980 horas/ano, conforme a fonte consultada.

Fonte - Adaptado de DINIZ (2011, p. 09).

Considerando que a Cia Ferro Ligas de Minas Gerais - Minasligas já opera por 38 anos (MINAS GERAIS, 2002, p. 03), a Ligas de Alumínio S.A - Liasa por 46 anos (LIASA, 2014) e a Inoculantes e Ferro Ligas Nipo-Brasileiros S/A. - Inonibrás está em atividade no local há 36 anos (INONIBRÁS, 2018), conclui-se que a exposição aos efeitos do MP é crônica. Há ainda fornos operando no local sem sistema de despoeiramento, dispositivo que, se instalado e operado adequadamente, reduz as emissões do MP gerado com uma eficiência aproximada de $99 \%$.

A Inonibrás instalou sistema de despoeiramento em seu Forno II em agosto de 1995 e em junho de 2013, no Forno I, antecipando-se aos prazos acordados com a Fundação Estadual do Meio Ambiente - FEAM (INONIBRÁS, 2018, p. 39).

Em 20 de janeiro de 2016 a Minasligas ainda não havia instalado filtro nos Fornos I, II e III, tanto que enviou para a SUPRAM-NM o Projeto Definitivo do Sistema de Despoeiramento para os Fornos. Esse envio foi em atendimento às novas condicionantes impostas quando da prorrogação da $2^{\mathrm{a}}$ Etapa do Acordo Setorial, sendo o prazo limite para instalação e operação dos filtros até 31 de dezembro de 2016 (MINAS GERAIS, 2016).

A Liasa, por sua vez, em junho de 2016 teve confirmada pelo órgão ambiental a instalação de filtro no Forno I, fato atestado em junho de 2016 (RICARDO CARNEIRO, 2016, p.15). Todavia, apenas três meses depois, encontrava-se inoperante, o que motivou aplicação de multa e embargo por parte dos agentes de fiscalização estadual. Na mesma ocasião, os fiscais verificaram a inexistência de obras de instalação de sistemas de despoeiramento nos Fornos II, III e IV, isso a menos de 100 dias para findar o último prazo (RICARDO CARNEIRO, 2016, p.11-12). Com base no exposto e considerando um cenário em que novos sistemas de despoeiramento não tenham sido instalados, estima-se que as atuais emissões de material particulado cheguem a $765 \mathrm{Kg} / \mathrm{h}$ por parte da Minasligas (25,81\%), $2.199,14 \mathrm{Kg} / \mathrm{h}$ por parte da Liasa $(74,19 \%)$, o que totaliza $2.964,14 \mathrm{Kg} / \mathrm{h}$. Esses números tomam por base a operação de todos os fornos, nas condições expostas na Tabela 1. Não foram consideradas as emissões dos fornos com filtros por razão de insignificância para o estudo em questão.

\section{COMPORTAMENTO DA PLUMA DE POLUENTES E AMEAÇAS À SAÚDE}

A Figura 6 registrou a paisagem vista a partir da margem esquerda do Rio São Francisco e flagra a exposição da área urbana de Pirapora aos poluentes oriundos das metalúrgicas instaladas no Distrito Industrial. As setas vermelha, verde e amarela indicam a posição das empresas Minasligas, Inonibrás e Liasa, respectivamente.

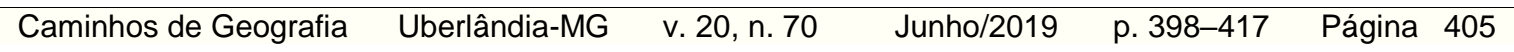


Figura 6 - Pluma de poluição sobre a cidade de Pirapora/MG.

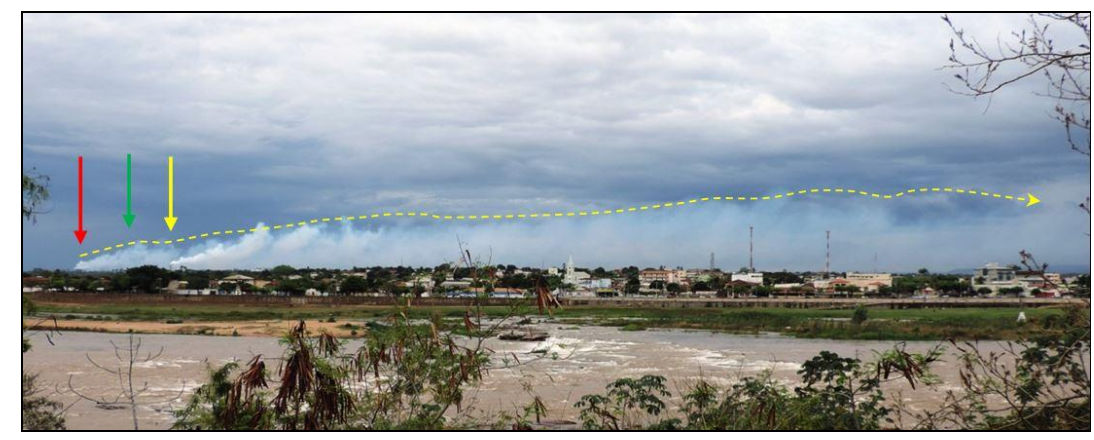

Fonte - Primeiro Autor (2016).

O registro fotográfico é de 04/10/2016, às 16h40min. Apesar do tempo nublado é perfeitamente possível observar a abrangência da pluma, delimitada na imagem pela linha pontilhada amarela. $O$ flagrante foi de um dos momentos em que os ventos se deslocaram em direção diferente ao seu comportamento mais comum. Conforme estudo realizado por Ribeiro et al. (2014, p.301) dados meteorológicos indicam predominância na direção dos ventos NE-SW (31,7\%), direção esta que corroborou com a análise feita pelos mesmos autores, quanto ao comportamento dos particulados, usando técnicas de geoprocessamento e sensoriamento remoto. Os particulados tenderam para W em $85 \%$, de 212 imagens de satélite analisadas pelos autores. A Figura 7 ilustra o comportamento predominante da pluma de particulados (mancha esverdeada) e a direção (seta pontilhada amarela), em relação às sedes municipais de Buritizeiro e Pirapora.

Figura 7 - Comportamento predominante da pluma de particulados.

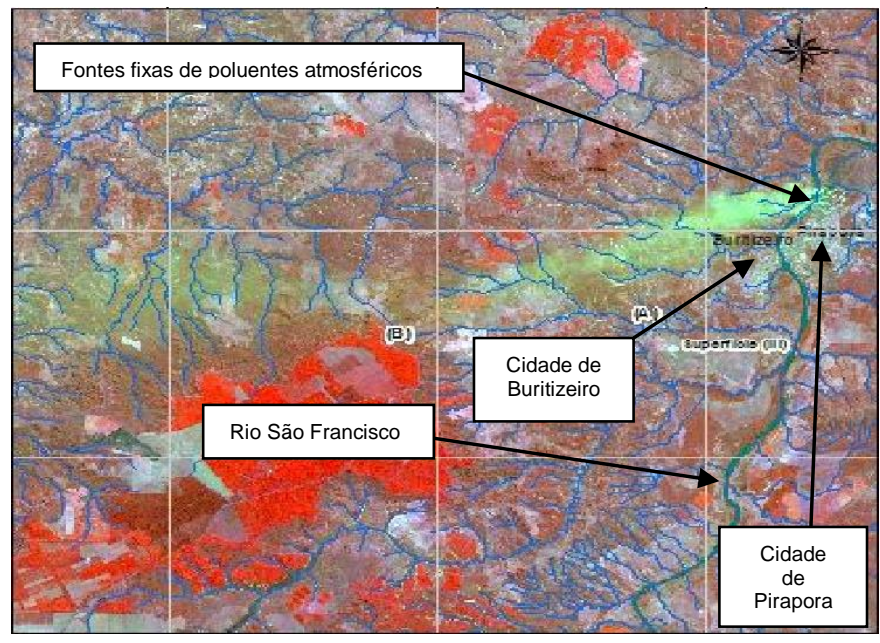

Fonte - RIBEIRO et al. (2014, p. 303) adaptado pelos Autores.

Condicionantes geomorfológicos e meteorológicos determinam o comportamento da pluma de poluentes que parte do DI. É o que Ribeiro (2016, p.87) afirmou, após usar de metodologia que mesclou o estudo do comportamento dos ventos, a geomorfologia local e imagens de satélites:

Os dados da movimentação dos poluentes obtidos neste estudo apontam para a necessidade de uma atenção para as áreas urbanas de Pirapora e Buritizeiro na estação úmida em que os ventos de norte adicionam um vetor de circulação da pluma para Sul, onde se localizam os centros urbanos. Além disso corredor geomorfológico de circulação da pluma de material particulado coincide com o espaço urbano dos municípios, expondo a população aos poluentes que podem ter efeitos crônicos na saúde. Neste contexto deve se ter atenção especial às crianças e aos idosos que são mais vulneráveis aos efeitos adversos da presença de partículas na atmosfera (RIBEIRO, 2016 p. 87).

$\begin{array}{llllll}\text { Caminhos de Geografia } & \text { Uberlândia-MG } & \text { v. 20, n. } 70 \quad \text { Junho/2019 } & \text { p. 398-417 } & \text { Página } 406\end{array}$


A preocupação da autora é respaldada por estudos diversos que apontam para uma correlação entre aumento da poluição atmosférica com o acréscimo nos casos de doenças e agravos, dentre as quais, destacam-se as que afetam o aparelho respiratório e o aparelho circulatório.

A poluição do ar vem sendo discutida em nível mundial desde a primeira década da criação da Organização Mundial da Saúde - OMS. Os trabalhos a respeito foram publicados pela primeira vez em 1957 e desde então a OMS aprofundou-se na busca da organização do conhecimento e desenvolvimento de ferramentas de auxílio ao planejamento de políticas públicas de controle da poluição do ar e seus efeitos sobre a saúde, como o estabelecimento de diretrizes globais para concentrações de poluentes atmosféricos (WHO, 2017, p. 01). Em 1972 os pesquisadores concordaram em estabelecer uma linha entre níveis de concentrações prováveis e não prováveis de produzirem efeitos adversos na saúde humana. Esse raciocínio foi ilustrado pela OMS na Figura 08:

Figura 8 - Espectro esquemático da resposta biológica à exposição ao poluente.

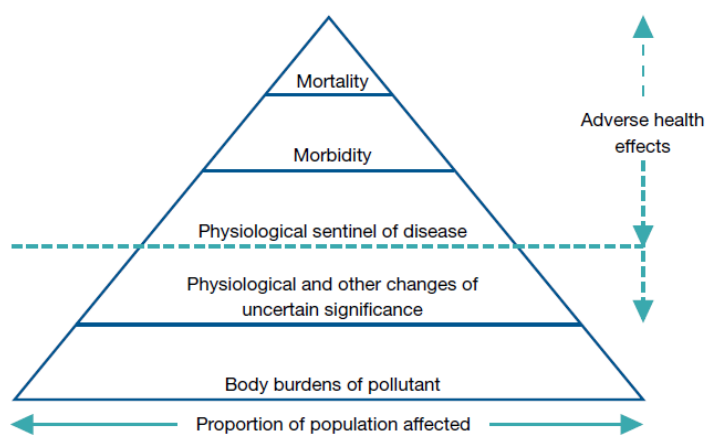

Fonte - WHO (2017, p.07).

Ao filtrar pesquisas na base de dados PubMed, referência internacional no auxílio à busca de trabalhos científicos da área da saúde, a pesquisadora Neide Regina Simões Olmo, bacharel e doutora em medicina, confirmou as evidências científicas dos efeitos adversos da poluição atmosférica na saúde humana. Ela chegou aos seguintes números: "Dos 32 estudos nacionais, 27 evidenciaram efeitos adversos na saúde humana, mesmo em concentrações menores do que as permitidas legalmente [...]" (OLMO, 2011). Quanto aos estudos internacionais: "Dos 112 estudos internacionais pesquisados, 78 demonstraram efeitos na saúde humana mesmo abaixo dos padrões legais permitidos [...]" (OLMO, 2011).

Embora os malefícios da poluição do ar sejam comumente associados a problemas nos pulmões e vias aéreas, ela pode danificar a maioria dos outros sistemas do corpo. Schraufnagel et al. (2018) a associaram aos mais variados diagnósticos, dentre os quais ao derrame, ao câncer de bexiga, a leucemia infantil, ao aumento do risco de demência e atraso no desenvolvimento psicomotor, a danos ao sistema imunológico, à osteoporose, ao agravamento da diabetes mellitos, dentre outras.

A exposição a material particulado no ar também está correlacionada a patologias subclínicas subjacentes à doença cardiovascular como a inflamação sistêmica e estresse oxidativo, aterosclerose, trombose, disfunção endotelial, hipertensão, remodelamento cardíaco e arritmia (HAMANAKA e MUTLU, 2018). Estudos epidemiológicos de grande porte realizados nos últimos anos forneceram evidências inequívocas de que a exposição ao material particulado no ar ambiente está associada a efeitos cardiovasculares e que os efeitos cardiovasculares podem ser muito mais adversos do que se pensava, representando um grande custo para a saúde pública (CASCIO e LONG, 2018, p. 307).

Nesse viés, Lipfert $(2018$, p.12) realizou pesquisa no Banco de Dados de publicações do National Institutes of Health MEDLINE para estudos de longo prazo que correlacionem causa e efeito entre poluição do ar e morbidade. O autor observou relacionamento significativo para desfechos menos graves, como pressão arterial, função pulmonar ou sintomas respiratórios, do que com a incidência de morbidades graves como câncer, DPOC, insuficiência cardíaca ou diabetes.

$\begin{array}{llllll}\text { Caminhos de Geografia } & \text { Uberlândia-MG } & \text { v. 20, n. } 70 & \text { Junho/2019 } & \text { p. 398-417 } & \text { Página } 407\end{array}$


Importante destacar que em uma investigação que utiliza o ser humano como bioindicador na busca da associação entre poluição do ar e morbidade humana, geralmente abrange-se uma vasta gama de doenças e agravos como um dos parâmetros analisados. Essas manifestações deletérias podem, obviamente, serem agravadas ou mesmo causadas por outros agentes que não a poluição atmosférica. A exposição a diferentes condições ambientais, hábitos alimentares e o tabagismo, sedentarismo, hereditariedade, dentre outras variáveis, atuam sobre as populações. Além da qualidade do ar, outros riscos ambientais, como excesso de calor, impactam a saúde promovendo respostas fisiológicas às mudanças ambientais (FINK et al., p. 295). Ademais, sendo um ambiente sem fronteiras físicas para a inevitável onipresença de poluentes, a atmosfera pode ser degradada por uma infinidade de agentes. O poluente $\mathrm{PM}_{10}$ deriva de fontes diversas, difusas e pontuais, naturais e antrópicas. Sua concentração no ar geralmente tem a colaboração de poeiras advindas de estradas e rodovias, obras de construção e demolição, mineração, incêndios florestais e poeira soprada pelo vento (DU et al., p. E-09)

Atenta a isso, a Organização Mundial da Saúde - OMS vem trabalhando na atualização do estabelecimento de Diretrizes Globais para a Qualidade do Ar ou do original, AQGs - air quality guidelines. Nessa atualização, está sendo considerado, dentro outros critérios, os efeitos da exposição ao pó mineral de origem natural e seus impactos sobre a saúde humana. Esse processo "[...] se beneficiará de novos estudos disponíveis considerando vários aspectos ambientais, sociais e condições de saúde [...]" (WHO, 2017, p. 27-28). Frente aos desafios de aumentar a confiabilidade dos resultados em investigações dessa natureza, estudos ecológicos com abordagem espacial sobre grupos de indivíduos são amplamente utilizados. Essas abordagens e seus resultados estão sendo chancelados pela comunidade científica, fato confirmado pelo elevado número de publicações e de periódicos internacionais, classificados com elevado fator de impacto, dedicados exclusivamente aos efeitos da poluição do ar sobre a saúde e o meio ambiente.

Citando pesquisas conduzidas em cidades do interior do Brasil quanto aos efeitos da poluição do ar sobre a ocorrência de morbidades cardiovasculares e respiratórias, Braga et al. (2007, p.571) estudaram o poluente $\mathrm{PM}_{10}$ (material particulado com diâmetro inferior a 10 micrômetros) e seus efeitos sobre a população da cidade de Itabira/MG, que é impactada por atividade mineraria. A investigação culminou com a conclusão de que essas atividades estão associadas ao aumento nos atendimentos de pronto-socorro por doenças respiratórias entre crianças e adolescentes e cardiovasculares entre adultos:

Aumentos de $10 \mu \mathrm{g} / \mathrm{m}^{3}$ no $\mathrm{PM}_{10}$ foram associados com aumentos nos atendimentos de pronto-socorro por doenças respiratórias de $4 \%$ (IC 95\%:2,2 5,8), no dia e no dia seguinte, para crianças menores de 13 anos, e de 12\% (IC 95\%:8,5-15,5), nos três dias subsequentes para os adolescentes entre 13 e 19 anos. Dentre os atendimentos por doenças cardiovasculares, o efeito foi agudo (4\%; iC 95\%: 0,8$8,5)$, principalmente para os indivíduos com idade entre 45 e 64 anos. Esses resultados mostram que o $\mathrm{PM}_{10}$ gerado principalmente através de mineracão a céu aberto pode acarretar prejuízos à saúde da população (BRAGA, et al., 2007, p. 577).

Em trabalho similar, Nardocci et al. (2013) estudaram séries temporais da poluição do ar $\left(\mathrm{PM}_{10}, \mathrm{SO}_{2}\right.$, $\mathrm{O}_{3}$ ) e internações hospitalares em Cubatão-SP e entre outras conclusões, afirmaram que:

Para cada incremento de $10 \mu \mathrm{g} / \mathrm{m}^{3}$ de $\mathrm{PM}_{10}$, encontrou-se um excesso de internacões de $4,25 \%$ (IC 95\%: 2,$82 ; 5,71$ ) ; 5,74\% (IC 95\%: 3,80; 7,71) e $2.29 \%$ (IC $95 \%: 0,86 ; 3,73)$ para doenças respiratórias totais, doenças respiratórias em menores de 5 anos e doenças cardiovasculares em maiores de 39 anos, respectivamente (NARDOCCI, et al., 2013, p.1867)

Como a operação das metalúrgicas em Pirapora/MG traz uma série de riscos para a saúde da população e para o meio ambiente, riscos estes ligados a fatores como a quantidade, tipo de poluente e comportamento da pluma de poluicão, a Superintendência Regional de Regularizacão Ambiental do Norte de Minas - SUPRAM-NM, órgão licenciador seccional da Secretaria de Estado de Meio Ambiente - SEMAD, impôs uma serie de condicionantes quando da renovação das licenças ambientais desses empreendimentos. Dentre elas, a obrigatoriedade do monitoramento da qualidade do ar. As três metalúrgicas, dividindo os custos e responsabilidades, implantaram duas Estaccões de Monitoramento cuja operação iniciou-se em 2008: Estação Faculdade de Tecnologia Alto Médio São Francisco - FUNAM, localizada a aproximadamente dois quilômetros (em linha reta) das chaminés da metalúrgica mais próxima e; Estaçáo Serviço Autônomo de Agua e Esgoto de Pirapora - SAAE, esta mais distante, a cinco quilômetros das chaminés. A Figura 9 ilustra a distribuição espacial da rede de monitoramento em relação às fontes fixas de poluentes:

Figura 9 - Localização das Estações de Monitoramento da Qualidade do Ar.

$\begin{array}{llllll}\text { Caminhos de Geografia } & \text { Uberlândia-MG } & \text { v. 20, n. } 70 & \text { Junho/2019 } & \text { p. 398-417 } & \text { Página } 408\end{array}$


Poluição atmosférica, problemas respiratórios e cardiovasculares: investigando o setor ferroligas em Pirapora/MG, Brasil
Gustavo Lino Mendonça Sandra Célia Muniz Magalhães Cássio Alexandre da Silva

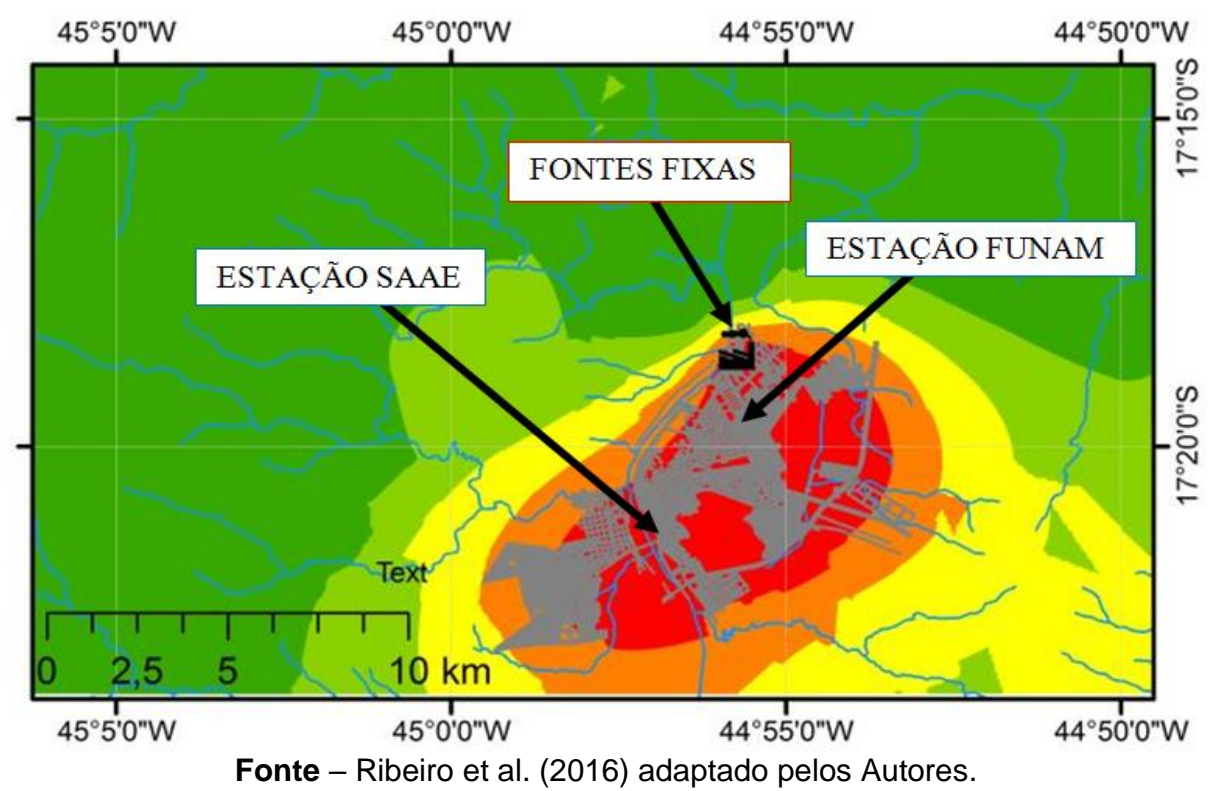

O monitoramento da qualidade do ar dedica-se a quantificar e medir as concentrações dos poluentes no ar ambiente, local onde pessoas, animais e plantas encontram-se expostos e podem vir a sofrer danos à saúde, entre outros efeitos negativos (FRONDIZI, 2008 p. 16).

As Figuras 10 e 11 apresentam os resultados apresentados pelas empresas junto ao órgão ambiental licenciador competente, conforme os registros da Estação de Monitoramento FUNAM, entre julho de 2012 a junho de 2014:

Figura 10. - Concentrações de $\mathrm{PM}_{10}$ registrados pela Estação FUNAM (jul/2012 a jun/2013).

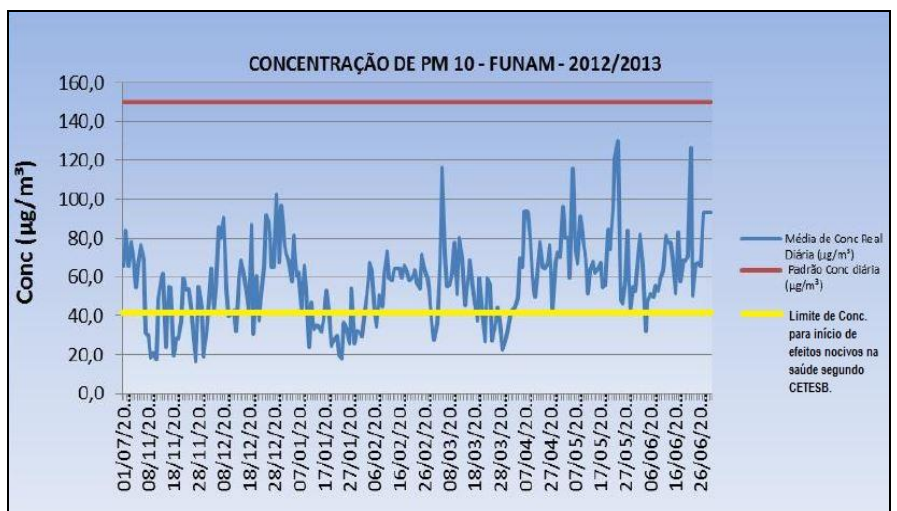

Fonte - Adaptado de LIASA (2014 p. 36).

Figura 11 - Concentrações de PM10 registrados pela Estação FUNAM (ago/2013 a jun/2014).

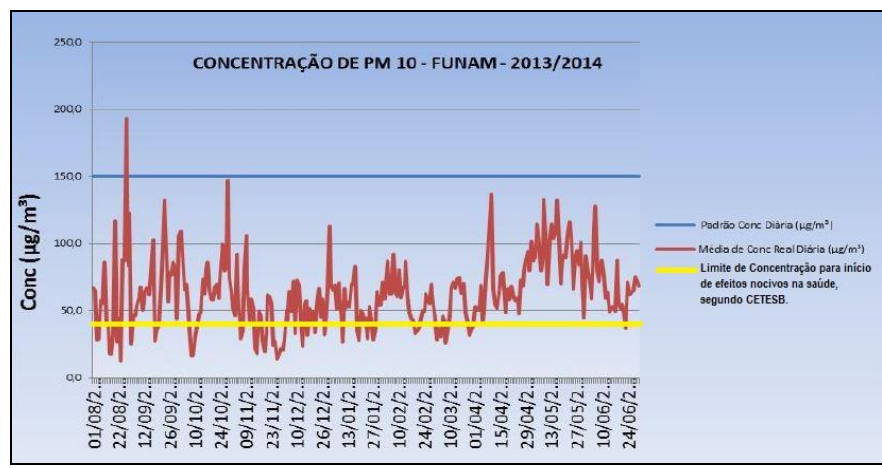

Fonte - Adaptado de LIASA (2014 p. 36).

Caminhos de Geografia Uberlândia-MG $\quad$ v. 20, n. $70 \quad$ Junho/2019 
Nos gráficos, adaptou-se do original uma linha horizontal amarela delimitando o nível de degradação da qualidade do ar a partir do qual, iniciam-se efeitos adversos à saúde $\left(40 \mathrm{ug} / \mathrm{m}^{3}\right)$, segundo a Companhia Ambiental do Estado de São Paulo - CETESB (SẢO PAULO, 2017). Num período de dois anos, a Estação FUNAM não excedeu, em amostras colhidas por 24hs, mais de uma vez ao ano a concentração de $150 \mathrm{ug} / \mathrm{m}^{3}$ (microgramas por metro cúbico de ar). O mesmo não pode ser afirmado para o outro parâmetro a ser considerado. A Resolução do Conselho Nacional do Meio Ambiente CONAMA 003/1990 dispunha que, para esse tipo de poluente, além da meta que foi atendida, o padrão de qualidade do ar não poderia apresentar Média Aritmética Anual - MAA maior que $50 \mathrm{ug} / \mathrm{m}^{3}$ (BRASIL, 1990).

Analisando os gráficos e consultando a Figura 12, verifica-se que, no período amostrado, ocorreu uma predominância da qualidade do ar moderada $\left(\mathrm{N}^{2}\right)$, os resultados das concentrações estiveram numa faixa que vai de $41 \mathrm{ug} / \mathrm{m}^{3}$ a $80 \mathrm{ug} / \mathrm{m}^{3}$. Essa condição pode ter contribuído para efeitos adversos, principalmente na população pertencente a grupos susceptíveis, composto por crianças, idosos e pessoas com doenças respiratórias e cardíacas.

Figura 12 - Qualidade do ar e efeitos à saúde.

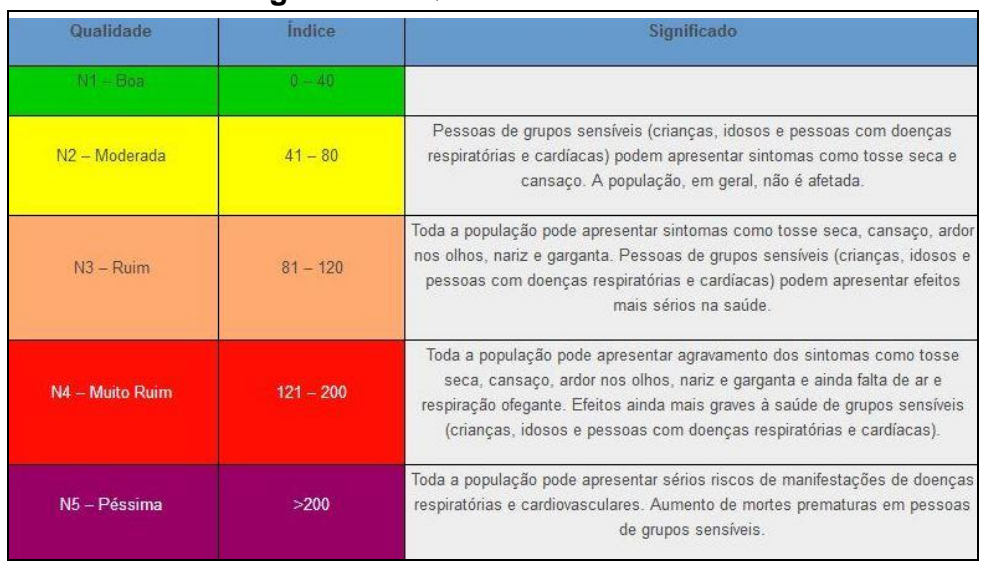

Fonte - SÃO PAULO (2017).

Observa-se em dados períodos a predominância de concentrações entre $81 \mathrm{ug} / \mathrm{m}^{3}$ a $120 \mathrm{ug} / \mathrm{m}^{3}$ de $\mathrm{PM}_{10}$, fato observado entre o final de abril de 2014 até maio do mesmo ano, espaço de tempo em que a qualidade do ar esteve ruim $\left(\mathrm{N}^{3}\right)$. Essa condição expôs toda a população ao desencadeamento de sintomas como cansaço, tosse seca, ardor nos olhos, nariz e garganta, além de falta de ar.

Atualmente encontra-se em vigor a Resolução CONAMA 491/2018, com valores de referência a serem monitorados ainda mais rigorosos que os anteriormente estabelecidos pela Norma revogada. A readequação se deu consideranđo os valores guia de qualidade do ar, recomendados pela OMS em 2005, além de continuar sendo parte estratégica do Programa Nacional de Controle da Qualidade do $\mathrm{Ar}$ - PRONAR como instrumentos complementares e referenciais (BRASIL, 2018).

RESULTADOS E DISCUSSÃO

A Figura 13 apresenta os resultados obtidos para a Taxa de Morbidade Populacional Geral:

Figura 13 - Taxa de Morbidade Populacional Geral - TMP-G por Território de Saúde.

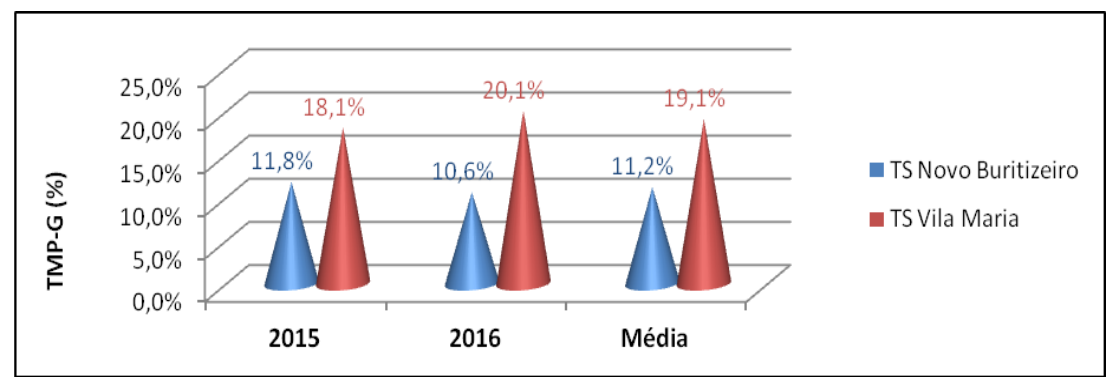

Fonte - Pesquisa direta (2017).

No ano de 2015 a Taxa de Morbidade Populacional Geral foi de 11,8\% na Unidade Básica de Saúde Novo Buritizeiro e 18,1\% na Unidade Básica de Saúde Vila Maria, ou seja, uma diferença absoluta (entre taxas) de 6,3\% e percentualmente, de 53,38\%. No ano seguinte, a diferença nos casos de Doenças e Agravos investigados entre os dois Territórios de Saúde aumentou, pois ocorreu uma queda na Taxa de Morbidade Populacional Geral na Unidade Básica de Saúde Novo Buritizeiro para

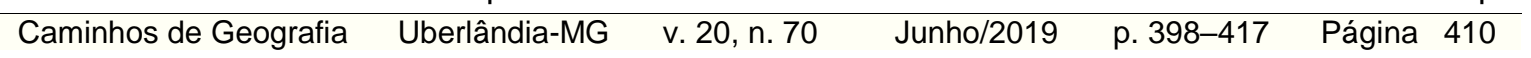


$10,6 \%$ e um aumento na Unidade Básica de Saúde Vila Maria, chegando a 20,1\%, fazendo com que a diferença entre taxas atingisse $9,5 \%$. Isso significa que, percentualmente, no Território de Saúde Vila Maria o número de Doenças e Agravos I e J foi $89,62 \%$ maior que no Território de Saúde Novo Buritizeiro. A média dos anos de 2015 e 2016 foram 11,2\% no Território de Saúde Novo Buritizeiro e $19,1 \%$ no Território de Saúde Vila Maria, uma diferença da Taxa de Morbidade Populacional Geral de $7,9 \%$ entre os Territórios de Saúde ou 70,53\% superiores no Território de Saúde Vila Maria (Tabela 2):

Tabela 2 - Resultados das Taxas de Morbidade Populacional Geral - TMP-G

\begin{tabular}{ccccc}
\hline Período & TSVM & TSNB & Diferença & Diferença (\%) \\
2015 & 18,1 & 11,8 & 6,3 & 53,38 \\
2016 & 20,1 & 10,6 & 9,5 & 89,62 \\
Média & 19,1 & 11,2 & 7,9 & 70,53 \\
\hline \multicolumn{5}{c}{ Fonte - Dados da Pesquisa (2017). }
\end{tabular}

Os resultados para o Índice de Morbidade Populacional Geral podem ser verificados na Figura 14:

Figura 14 - Índice de Morbidade Populacional Geral - IMP-G por Território de Saúde.

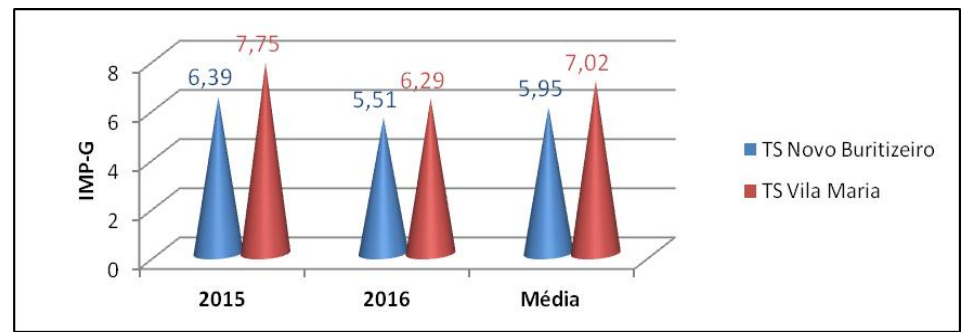

Fonte - Pesquisa direta (2017).

Para a população do Território de Saúde Novo Buritizeiro os resultados foram: 6,39, 5,51 e 5,95 para 2015, 2016 e média, respectivamente. A população do Território de Saúde Vila Maria apresentou Indice de Morbidade Populacional Geral superiores nos dois anos e consequentemente, na média, sendo: 7,75, 6,29 e 7,02, nessa mesma ordem. A Tabela 03 resume os resultados:

\begin{tabular}{|c|c|c|c|c|}
\hline $\begin{array}{c}\text { Período } \\
2015 \\
2016 \\
\text { Média }\end{array}$ & $\begin{array}{l}\text { TSVM } \\
7,75 \\
6,29 \\
7,02\end{array}$ & $\begin{array}{l}\text { TSNB } \\
6,39 \\
5,51 \\
5,95\end{array}$ & $\begin{array}{c}\text { Diferença } \\
1,36 \\
0,78 \\
1,07\end{array}$ & $\begin{array}{c}\text { Diferença (\%) } \\
21,28 \\
14,15 \\
17,98\end{array}$ \\
\hline
\end{tabular}

Analisando a Figura 14 e a Tabela 3, observa-se uma coerência entre os dois Territórios de Saúde no que diz respeito ao comportamento do índice. Ocorreu uma queda de 2015 para 2016 e os valores das quedas foram aproximados (1,46 Vila Maria e 0,88 Novo Buritizeiro). A ausência de informações exatas sobre os ritmos de produção nos períodos analisados impede que seja levantada a hipótese se haveria correlacão entre uma eventual reducão na operação das metalúrgicas e a queda do índice. Submetendo os Gráficos representados nas Figuras 13 e 14 a uma análise conjunta, chega-se à conclusão de que tanto o Indice de Morbidade Populacional Geral quanto a Taxa de Morbidade Populacional corroboraram-se no sentido de que a população do Território de Saúde Vila Maria, no período estudado, apresentou uma incidência de Doenças e Agravos respiratórios e cardiovasculares superior à apresentada pela população do Território de Saúde Novo Buritizeiro. Isso ocorreu nos dois anos pesquisados e consequentemente, na média deles. Tal fato coloca o presente artigo em consonância com os trabalhos de Braga et al. (2007), Nardocci et al. (2013), Cruz et al. (2015), Szyszkowicz (2018), Silveira e Junger (2018), Qu Y (2018), Hamanaka e Mutlu (2018), Nhung, et al. (2018), Cascio e Long (2018) e de Lipfert (2018) no que diz respeito à poluição do ar e efeitos adversos na saúde de populações expostas. Reforça ainda o status dado pela comunidade científica e a crescente preocupação da Organização Mundial da Saúde (WHO, 2017), em seus esforços de conscientizar gestores públicos e privados, donos dos meios de produção, profissionais da saúde, e da população em geral, a respeito dos perigos de se respirar em ambientes poluídos.

Passa-se aos resultados das taxas e índices da ocorrência de Doenças e Agravos por faixa etária. Salienta-se que não foi considerada a distribuição da população (em termos quantitativos) por grupos etários. A Figura 15 apresenta os resultados da incidência, por faixa etária, de Doenças e agravos cardiovasculares (CID-10 100-199) para os diferentes grupos etários: 
Figura 15 - Taxa de Morbidade Populacional de doenças e agravos do aparelho circulatório, por Território de Saúde e por faixa etária.

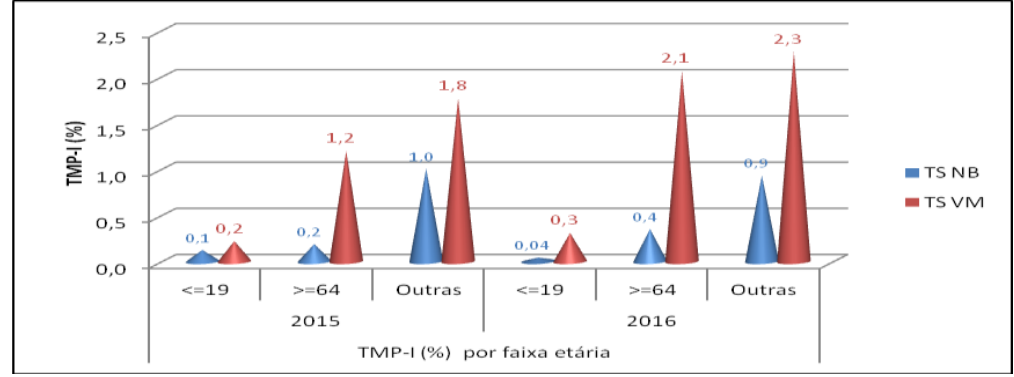

Fonte - Pesquisa direta (2017).

O Intervalo da população acima de 19 anos e abaixo de 64 anos foi a que apresentou maiores taxas de doencas e agravos cardiovasculares, sendo 1,0\% e 1,8\% para 2015-2016, Território de Saúde Novo Buritizeiro e Vila Maria, respectivamente. No Território de Saúde Vila Maria, os índices apresentados pela população idosa aproximaram-se do grupo que imediatamente os antecede, batendo na casa dos 1,2\% em 2015 e 2,1\% em 2016. Fato não observado no Território de Saúde Novo Buritizeiro, que ficou em 0,2\% em 2015 e 0,4\% em 2016, indicando que os habitantes do Território de Saúde Vila Maria foram mais susceptíveis a problemas cardiovasculares. Para os dois territórios, a população jovem foi a que apresentou os menores resultados.

Ainda que o que foi apurado aponte para a população intermediária como a detentora do maior número de casos, os idosos, proporcionalmente, compõem o extrato mais afetado por problemas cardiovasculares. Isso porque o Censo do IBGE (2010) apontou que, em Buritizeiro, a população com 65 anos ou mais era de 1.557 pessoas (5,78\%). Os jovens e criancas até 19 anos, $10.431(38,74 \%)$ e no grupo dos maiores de 19 e menores que 65 anos, 14.934 (55,48\%). Isso significa que, desprezando outras variáveis (distribuição por bairros, meio rural e urbano, etc.), estatisticamente os grupos populacionais maiores tenderiam a procurar mais a Unidade Básica de Saúde para consultar $\mathrm{e}$, por consequência, influenciar nas taxas de morbidade motivadas por problemas do aparelho circulatório (I) aparelho respiratório $(\mathrm{J})$ e Geral (ambas). Confirmou-se a tendência apontada por diversos estudos dentre os quais, os conduzidos por de Du et al. (2016) e Qu et al. (2018), quanto à maior predisposição dos idosos ao desencadeamento de problemas cardiovasculares causados ou agravados pela poluição do ar por material particulado.

A Figura 16 evidencia que os jovens e crianças são os que mais apresentaram diagnósticos de doenças e agravos do sistema respiratório, independentemente do ano e do território de saúde:

Figura 16 - Taxa de Morbidade Populacional de doenças e agravos do aparelho respiratório por Território de Saúde e por faixa etária.

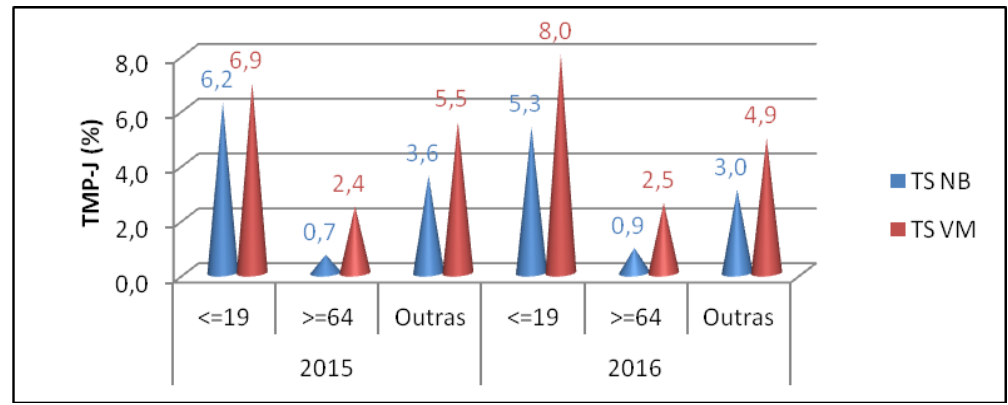

Fonte - Pesquisa direta (2017).

No Território de Saúde Novo Buritizeiro a Taxa de Morbidade Populacional - J (doenças e agravos do aparelho respiratório) entre a população de dezenove anos ou menos foi de 6,2\% em 2015 e 5,3\% em 2016, superando em 5,5\%,4,4\%, nessa ordem, as taxas apresentadas pela populacão idosa e $2,6 \%$ e $2,3 \%$ superiores às taxas da população de faixa etária intermediária. Esses resultados estão de acordo com os trabalhos de Nhung et al. (2018) no que diz respeito à maior susceptibilidade de crianças apresentarem problemas respiratórios por exposição a poluentes atmosféricos, se comparadas a adultos. Junger e Gouveia (2018) também vão nessa direção, eles constataram a diferenciação dos efeitos do $\mathrm{PM}_{10}$ sobre as faixas etárias até 14 anos com um aumento no risco de morte por problemas respiratórios. O Gráfico a seguir (Figura 17) faz a junção dos diagnósticos I (no aparelho circulatório) e J (no aparelho respiratório), por faixas e Território de Saúde, o que convencionou-se nomear de Taxa de Morbidade Populacional Geral - TMP-G, por faixa etária:

$\begin{array}{llllll}\text { Caminhos de Geografia } & \text { Uberlândia-MG } & \text { v. 20, n. 70 } & \text { Junho/2019 } & \text { p. 398-417 } & \text { Página } 412\end{array}$


Figura 17 - Taxa de Morbidade Populacional Geral (I e J) por Território de Saúde e por faixa etária.

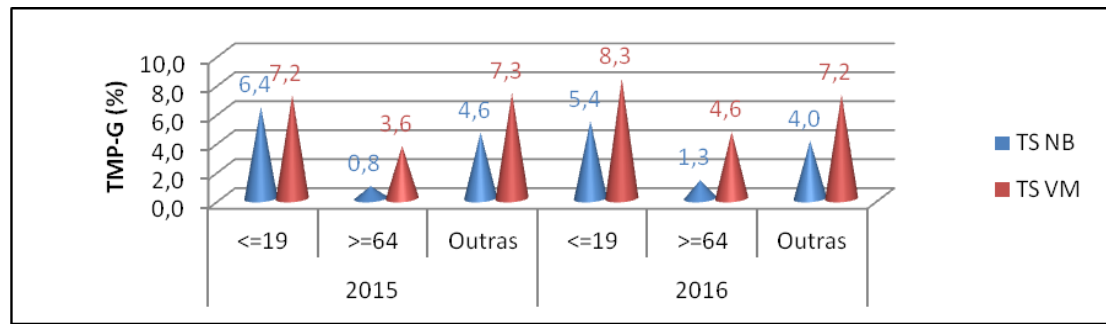

Fonte - Dados da Pesquisa (2017)

Observa-se que a disparidade nos diagnósticos do aparelho circulatório entre Territórios de Saúde (ver Figura 15) foi ocultada ao se mesclar com os diagnósticos de doenças e agravos do aparelho respiratório, por serem estes diagnósticos muito mais frequentes que aqueles. Todavia, a leitura do Gráfico 17 deixa claro que nos dois anos pesquisados a população do Território de Saúde Vila Maria apresentou maiores taxas de doenças e agravos de ambos os aparelhos (respiratório e circulatório) do que a população do Território de Saúde Novo Buritizeiro e ainda, a população jovem, seguida de outras, foram as com maior morbidade.

Em síntese, a sequência dos últimos três gráficos vem confirmar que a população de jovens e crianças são as que mais apresentam morbidades respiratórias e menos cardiovasculares, independentemente do ano e do Território de Saúde, seguida da população com idade intermediária.

Ainda que as concentrações de $\mathrm{PM}_{10}$ no ar podem ter a colaboracão de diferentes fontes, naturais e antrópicas, registra-se que na área pesquisada não há outras fontes de poluição atmosférica de grande porte em operação. A frota de veiculos automotores circulante é pouco significativa, não há número excessivo de pequenos empreendimentos (lava-jatos e oficinas de pintura e lanternagem de autos, marmorarias, entre outros) com potencial poluidor/degradador do ar, que poderiam interferir nos resultados. Tão pouco, atividades como a queima de cana, armazenamento e refinamento de combustíveis, indústrias químicas produtoras ou consumidoras de produtos voláteis, mineração a céu aberto, ou outros, capazes de degradar a qualidade do ar de forma significativa, a ponto de confundir com a poluição causada pelas fontes fixas pesquisadas.

\section{CONSIDERAÇÕES FINAIS}

Ao compararmos dois Territórios de Saúde localizados em Buritizeiro, um (Território de Saúde Vila Maria) quase que por completo sobreposto à área de maior risco ambiental e o outro (Território de Saúde Novo Buritizeiro), em situação oposta, constatamos que o primeiro apresentou taxas de morbidade (doenças e agravos respiratórios e cardiovasculares) superiores ao segundo em 53,38\% e $89,62 \%$ para os anos de 2015 e 2016 , respectivamente e em média, $70,53 \%$.

Essas disparidades poderiam ser ainda mais acentuadas, a maioria das vias públicas que servem o Território de Saúde Novo Buritizeiro são de terra batida e ainda, as características do solo daquela localidade favorecem as emissões fugitivas. Em situação oposta encontra-se o Território de Saúde Vila Maria, onde predomina pavimento asfáltico que, em tese, minimizam esse tipo de emissão e consequentemente, a ocorrência de doenças e agravos pesquisados.

Confirmou-se também, no recorte espacial e temporal, que existe uma distribuição diferenciada das morbidades do aparelho circulatório e do aparelho respiratório por faixas etárias, colocando os jovens e criancas como os que mais sofrem com morbidades respiratórias, seguida da faixa etária intermediária, cujos índices mais elevados de morbidades foram os do sistema cardiovascular. Se considerada a proporcionalidade da população por grupos etários, pode-se inserir o grupo dos idosos (64 anos ou mais) como o mais afetado por problemas cardiovasculares no Território de Saúde Vila Maria e o segundo, independente do Território de Saúde, de morbidades respiratórias.

A hipótese foi confirmada. Para o período em questão a população que vive no Território de Saúde da Unidade Básica de Saúde Vila Maria apresentou maior susceptibilidade de desencadeamento de doenças respiratórias e cardiovasculares e a razão para tal é o fato do Território de Saúde encontrarse inserido quase que totalmente dentro da área de maior risco ambiental para poluentes atmosféricos ao passo que o território da Unidade Básica de Saúde Novo Buritizeiro encontra-se quase que totalmente fora dessa área, deixando a população menos exposta.

Por meio do método indutivo, há de se considerar, portanto, que grande parte da populacão das cidades de Buritizeiro e Pirapora respiram em uma atmosfera degradada por poluentes originários das fontes fixas das empresas produtoras de ferroligas e metais não ferrosos, instaladas e operando em Pirapora. Atualmente, excetuam-se os lançamentos da metalúrgica Inonibrás, por ter concluído a instalação de sistemas de despoeiramento no ano de 2013 e partindo do pressuposto de que esses mesmos sistemas encontram-se operando em condiç̃es adequadas. Inclui-se as fontes fixas, sem filtro, da Empresa Minasligas que hoje estima-se, seja responsavel por aproximadamente $25,81 \%$ da carga poluidora. Inclui-se também a das fontes fixas da Liasa, com potencial poluidor estimado em $74,19 \%$ do total gerado de Material Particulado lancado na atmosfera pelas chaminés dos fornos das metalúrgicas do Setor investigado, instaladas em Pirapora. Conclui-se ainda que tal exposição eleve

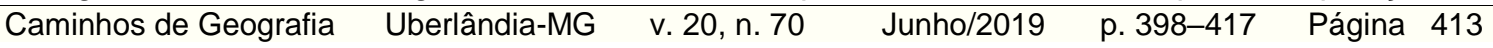


sobremaneira a probabilidade de desencadeamento de doenças e agravos respiratórios e cardiovasculares nessa mesma população.

Tais conclusões não esgotam o tema e por si só não devem ser tomadas como absolutas. Há fragilidades que devem ser consideradas. Os estudos epidemiológicos possuem seus pontos fortes e fracos, incluso o estudo ecológico utilizado. Investigaçôes conduzidas por meio de outros métodos, com outras variáveis temporais e espaciais, podem ser elaboradas e seus resultados confrontados com os demais.

A abordagem espacial como critério de diferencial das populações mais ou menos expostas a poluição demonstrou-se aplicável. Muitas das pesquisas consultadas utilizaram-se como parâmetro confrontador das taxas e índices de morbidade e mortalidade, os resultados oficiais de concentrações de poluentes registrados em estações de monitoramento (por frações de tempo que vão de horas a anos). E recomendável que o aprofundamento ou replicação desse estudo incorpore isso, além de variáveis meteorológicas, dentre outras como socioeconômicas, de gênero, relativas a hábitos alimentares, à prática de atividades físicas e ao tabagismo, culturais, dentre tantas outras. $\mathrm{O}$ artigo demonstrou as potencialidades de uma abordagem da temática via produção de dados primários coletados na atenção primária em detrimento do uso de dados da atenção secundária e terciária, mais comuns na produção científica, nesta seara.

Os resultados aqui expostos podem servir de apoio na implementação de políticas públicas voltadas à promoção da saúde e do meio ambiente, principalmente em escala local. As discussões no âmbito dos processos de regularização ambiental podem ganhar novos ingredientes ao se questionar 0 monitoramento da qualidade do ar realizado pelas metalúrgicas do Setor Ferroligas, como único parâmetro balizador dos níveis de segurança do ar respirado pela população sob influência.

É extremamente pertinente que os municípios de Pirapora e Buritizeiro criem sua própria rede de monitoramento da qualidade do ar, totalmente independente e no caso de Buritizeiro, com estações de monitoramento distribuídas em seu território, atualmente ausentes, apesar de ser diretamente afetado. Importante também que essas estações enviem dados diários a um sistema de informações ambientais, dando a devida publicidade em um ambiente web, meio de baixo custo com alcance instantâneo de massas. Demais municípios brasileiros, especialmente do interior, desprovidos de instrumentos de aferição da qualidade do ar, podem começar a considerar fazê-lo dado o grau de importância da relação saúde e qualidade da atmosférica respirável.

\section{AGRADECIMENTOS}

Os autores agradecem a Secretaria Municipal de Saúde do Município de Buritizeiro e aos profissionais das Unidades Básicas de Saúde dos PSF Novo Buritizeiro e Vila Maria.

\section{REFERÊNCIAS}

ANJOS, R. D. dos et al. Adição de microssílica e a secagem de concretos refratários. Cerâmica, São Paulo, v. 50, n. 316, p. 331-335, Dec. $2004 . \quad$ Available from $<$ http://www.scielo.br/scielo.php?script=sci_arttext\&pid=S0366-

69132004000400008\&lng=en\&nrm=iso>. access on 06 Jan. 2019. https://doi.org/10.1590/S036669132004000400008

BRAGA, A. L. F. et al. Associação entre poluição atmosférica e doenças respiratórias e cardiovasculares na cidade de Itabira, Minas Gerais, Brasil. Cad. Saúde Pública, Rio de Janeiro, v. 23, supl. $\quad$ 4, p. S570-S578, 2007. Available

from $<$ http://www.scielo.br/scielo.php?script=sci_arttext\&pid=S0102

311 X2007001600017\&lng=en\&nrm=iso>. access on 06 Jan. 2019. https://doi.org/10.1590/S0102$311 \times 2007001600017$

BRAGA, B. et al. Introdução à engenharia ambiental. 2. Ed. São Paulo: Pearson, 2010.

BRASIL. Conselho Nacional do Meio Ambiente - CONAMA. Resolução nº. 491de 19 de novembro de 2018. Dispõe sobre padrões de qualidade do ar. Disponível em: < http://www2.mma.gov.br/port/conama/legiabre.cfm?codlegi=740>. Acesso em: 02 jan 2019.

Resolução nํ․ 003 de 19 de junho de 1990. Dispõe sobre padrões de qualidade do ar, $\begin{array}{lccc}\text { previstos } & \text { no } & \text { PRONAR. } & \text { Disponível }\end{array}$

CASIO, W. E.; LONG, T. C. Ambient Air Quality and Cardiovascular Health: Translation of Environmental Research for Public Health and Clinical Care. North Carolina Medical Journal NCM, v. 79, no 05, Sept. Octo 2018. Disponível em: <

$\begin{array}{llllll}\text { Caminhos de Geografia } & \text { Uberlândia-MG } & \text { v. 20, n. 70 } & \text { Junho/2019 } & \text { p. 398-417 } & \text { Página } 414\end{array}$


http://www.ncmedicaljournal.com/content/79/5/306.full>. Acesso em: 06 jan. 2019. https://doi.org/10.18043/ncm.79.5.306

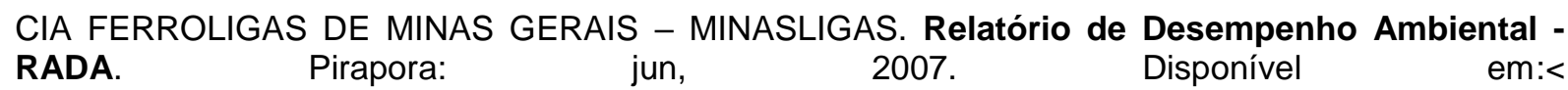
http://www.siam.mg.gov.br/siam/lc/2007/0001619840132007/3239952007.pdf> Acesso em: 29 dez. 2018.

CRUZ, A.M.J. et al. Association between atmospheric pollutants and hospital admissions in Lisbon. Environmental Science and Pollution Research, v. 22, n. 7, p. $5500-5510,2015$. Disponível em:< https://www.ncbi.nlm.nih.gov/pubmed/25471710>. Acesso em: 06 jan. 2019. https://doi.org/10.1007/s11356-014-3838-z

DELLAMANO, J. C. 1995. Uso de microssílica como aditivo na imobilização de rejeitos radioativos em cimento. 1995. 66 p. Dissertação (Mestrado em Ciências de Reatores Nucleares de Potência e Tecnologia do Combustível Nuclear) - Instituto de Pesquisas Energéticas e Nucleares IPEN - Universidade de São Paulo - USP. São Paulo.

DINIZ, P. S. Parecer Técnico (ID CEAT: 12255238): Valoração dos danos ambientais em virtude da prorrogação do prazo para implantação dos filtros. Ministério Público do Estado de Minas Gerais MP / Procuradoria Geral de Justiça / Centro de Apoio Técnico - CEAT: Belo Horizonte, 2011.

DU, Y. et al. Air particulate matter and cardiovascular disease: the epidemiological, biomedical and clinical evidence. Journal of thoracic disease, vol. 8,1 (2016): E8-E19. Aviable from:< https://www.ncbi.nlm.nih.gov/pmc/articles/PMC4740122/>. Access on 06 Jan. 2019.

FINK, R. et al. Symptomatic response of the elderly with cardiovascular disease during a heat wave in Slovenia. Cent Eur J Public Health, 2017/12/30 2017, vol. 25, no. 4, p. 293-298. Disponível em:< https://cejph.szu.cz/pdfs/cjp/2017/04/09.pdf>. Acesso em: $06 \quad$ jan. 2019. https://doi.org/10.21101/cejph.a4496

FRONDIZI, Carlos Alberto. Monitoramento da qualidade do ar: teoria e prática. Rio de Janeiro: Epapers, 2008.

FUNDAÇÃO NACIONAL DA SAÚDE - FUNASA. Textos de Epidemiologia para Vigilância Ambiental em Saúde. Coord. Volney de M. Câmara. Brasília: Ministério da Saúde, 2002.

GOUVEIA, N. et al. Effects of air pollution on infant and children respiratory mortality in four large Latin-American cities, Environmental Pollution, v. 232, 2018, Pages 385-391. Disponível em:<http://www.sciencedirect.com/science/article/pii/S0269749117313568>. Acesso em: 06 jan. 2019. https://doi.org/10.1016/j.envpol.2017.08.125

HAMANAKA, R. B.; MUTLU, G. M. Particulate Matter Air Pollution: Effects on the Cardiovascular System. Frontiers in Endocrinology, v.9, 2018, article 680, ISSN 1664-2392, $\mathrm{DOI}=10.3389 /$ fendo.2018.00680. Aviable from:< https://www.frontiersin.org/article/10.3389/fendo.2018.00680>. Access on 03 jan. 2019.

INOCULANTES E FERRO LIGAS NIPO-BRASILEIROS S.A - INONIBRÁS. Relatório de Desempenho Ambiental - RADA. Pirapora: jan. 2018. Disponível em:< http://www.siam.mg.gov.br/siam/lc/2018/0005219790072018/0516942018.pdf >. Acessado em: 29 dez. 2018.

INSTITUTO BRASILEIRO DE GEOGRAFIA E ESTATÍSTICA-IBGE. Sinopse do Censo
demográfico em:<https://censo2010.ibge.gov.br/sinopse/index.php?dados=29\&uf=31>. Acesso em 03 Dez. 2017.

LIANG, $\mathrm{H}$. et al. Short-term effects of fine particulate matter on acute myocardial infractionmortality and years of life lost: A time series study in Hong Kong. Sci Total Environ, v.615, p. 558-563. Disponível $\quad$ em:< https://www.sciencedirect.com/science/article/pii/S0048969717326189?via\%3Dihub>. Acesso em: 06 jan. 2019. https://doi.org/10.1016/i.scitotenv.2017.09.266

LIASA. Relatório de Avaliação de Desempenho Ambiental. Pirapora: 2014. Disponível em:< http://www.siam.mg.gov.br/siam/lc/2014/0005019790062014/9188962014.pdf>. Acesso em: 29 dez. 2018.

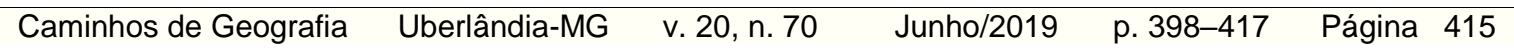


LIPFERT, F.W. Long-term associations of morbidity with air pollution: A catalog and synthesis. Journal of the Air \& Waste Management Association, v. 68, p. 12-28, 2018. Disponível em:< https://www.tandfonline.com/doi/citedby/10.1080/10962247.2017.1349010?scroll=top\&needAccess=tr ue>. Acesso em: 06 jan. 2019. https://doi.org/10.1080/10962247.2017.1349010

MINAS GERAIS. Secretaria de Estado de Meio Ambiente e Desenvolvimento Sustentável. Fundação Estadual do Meio Ambiente - FEAM. Relatório: Levantamento da Situação Ambiental e Energética do Setor de Ferroligas e Silício Metálico no Estado de Minas Gerais, com Prospecção de Ações para o Desenvolvimento Sustentável da Atividade - Relatório de Requisitos Legais: 2010. Disponível<em: http://www.feam.br/images/stories/arquivos/producaosustentavel/levantamento_situacao_setor_ferroli gas_requisitos_legais.pdf>. Acesso em: 13 abr. 2017.

MINAS GERAIS. Secretaria de Estado de Meio Ambiente e Desenvolvimento Sustentável - SEMAD. Superintendência Regional de Meio Ambiente e Regularização Ambiental do Norte de Minas SUPRAM-NM. Minasligas - Relatório de Desempenho Ambiental - RADA, 2002. Processo 0016/1984/013/2007- Cia Ferroligas Minas Gerais - MINASLIGAS. Disponível em:< http://www.siam.mg.gov.br/siam/lc/2007/0001619840132007/3239952007.pdf>. Acesso em: 06 jan. 2019.

. Minasligas - CFML 007/2016 (Ofício), 2016. Processo 016/1984/017/2012. Pedido de Vistas em 27, mar. 2017.

SILVEIRA, I.; JUNGER, W. L. Green spaces and mortality due to cardiovascular diseases in the city of Rio de Janeiro. Rev. Saúde Pública, São Paulo, v. 52, 49, 2018. Available from $<$ http://www.scielo.br/scielo.php?script=sci_arttext\&pid=S0034-

89102018000100241\&lng=en\&nrm=iso>. access on 28 Dec. 2018. Epub May 03, 2018. https://doi.org/10.11606/S1518-8787.2018052000290

MINISTÉRIO DA SAÚDE. Centro Colaborador da OMS para a classificação de doenças em português - $\quad$ CBCD. $\quad$ CID-10. Datasus. Disponível em:< http://www.datasus.gov.br/cid10/V2008/cid10.htm>. Acesso em: 02 jan. 2019.

Portaria 104, de 25 de janeiro de 2011. Define as terminologias adotadas em legislação nacional, conforme o disposto no Regulamento Sanitário internacional (RSI), a relação de doenças e agravos e eventos em saúde pública de notificação compulsória em todo o território nacional e estabelece fluxo, critérios, responsabilidades e atribuições aos profissionais e serviços de saúde. Disponível em:http://bvsms.saude.gov.br/bvs/saudelegis/gm/2011/prt0104_25_01_2011.html. Acesso em: 17 jun. 2017.

MONKEN, M.; BARCELOS, C. O Território na Promoção e Vigilância em Saúde. Disponível em: $<$ <ttp://www.epsjv.fiocruz.br/pdtsp/index.php?s_livro_id=6\&area_id=4\&autor_id=\&capitulo_id=22\&sub capitulo_id=59\&arquivo=ver_conteudo_2>. Acesso em: 17 jun. 2017.

NARDOCCI, A. C. et al. Poluição do ar e doenças respiratórias e cardiovasculares: estudo de séries temporais em Cubatão, São Paulo, Brasil. Cad. Saúde Pública, Rio de Janeiro, v. 29, n.9, p.18671876, Sept. 2013. Disponível em: $<$ http://www.scielo.br/scielo.php?script=sci_arttext\&pid=S0102311X2013000900025\&lng=en\&nrm=iso >. Acesso em: 22 jun. 2017. https://doi.org/10.1590/S0102-311X2013001300025

NHUNG, T. T. N., et al. Acute effects of ambient air pollution on lower respiratory infections in Hanoi children: An eight-year time series study, Environment International, v. 110, 2018, p.139-148, ISSN 0160-4120, $\quad$ https://doi.org/10.1016/j.envint.2017.10.024.

Aviable from:<http://www.sciencedirect.com/science/article/pii/S0160412017309996>. Access on: 02 jan. 2019. https://doi.org/10.1016/j.envint.2018.06.033

OLMO, N. R. S. Poluição atmosférica e exposição humana: a evolução científica epidemiológica e sua correlação com o ordenamento jurídica. 2011. Tese (doutorado em Patologia) - Faculdade de Medicina, Universidade de São Paulo, São Paulo, 2011. doi: 10.11606/T.5.2011.tde-24052011162041. Acesso em: 29 jun. 2017. https://doi.org/10.11606/T.5.2011.tde-24052011-162041

ORGANIZAÇÃO PAN-AMERICANA DA SAÚDE / ORGANIZAÇÃO MUNDIAL DA SAÚDE. OMS divulga nova Classificação Internacional de Doenças (CID-11). Disponível em:<

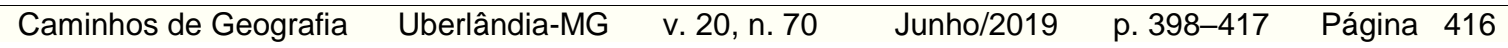


https://www.paho.org/bra/index.php?option=com_content\&view=article\&id=5702:oms-divulga-novaclassificacao-internacional-de-doencas-cid-11\&ltemid=875>. Acesso em: 30 dez. 2018.

PREFEITURA MUNICIPAL DE BURITIZEIRO. Fotos Aéreas da Cidade de Buritizeiro/MG. 2013. Fotos coloridas. $4.288 \times 2.884$ pixels, $300 \mathrm{DPI}$.

$\mathrm{QU}, \mathrm{Y}$. et al. Short-term effects of fine particulate matter on non-accidental and circulatory diseases mortality: A time series study among the elder in Changchun. PLoS ONE 13(12): e0209793. https://doi.org/10.1371/journal.pone.0209793.

Disponível

em:< https://journals.plos.org/plosone/article?id=10.1371/journal.pone.0209793>. Acesso em: 06 jan. 2019. https://doi.org/10.1371/journal.pone.0209793

RIBEIRO, E. V. 2016. A poluição atmosférica por material particulado relacionada com a indústria metalúrgica na região de Pirapora/MG/Brasil. Tese (doutorado). Universidade Federal de Minas Gerais - UFMG. Instituto de Geociências - Departamento de Geografia. Belo Horizonte. 151f.

RIBEIRO, E. V. et al. (2014). Corredores geomorfológicos e a circulação dos particulados atmosféricos do distrito industrial de Pirapora - MG. Revista Geonorte. Manaus, Edição

RICARDO CARNEIRO ADVOGADOS ASSOCIADOS. Defesa Administrativa: Auto de Infração 94752/2016. Ligas de Alumínio S.A. - LIASA, 2016. Disponível em:< file://C:/Users/Cliente/Downloads/2-_LIASA_-_Defesa\%20(2).pdf>. Acesso em: 06 jan. 2019.

Especial, v. 5, n. 23, pp. 299-304. Disponível em:< http://www.periodicos.ufam.edu.br/revistageonorte/article/view/1712>. Acesso em: 06 jan. 2019.

SANTOS, J. O.; ROSS, J. L.S. Fragilidade ambiental urbana. Revista da ANPEGE, v.8, n.10, p.127144, ago./dez. 2012. Disponível em: < http://ojs.ufgd.edu.br/index.php/anpege/article/view/6511/3503 >. Acesso em: 06 de jan. de 2019. https://doi.org/10.5418/RA2012.0810.0009

SÃO PAULO. Secretaria do Meio Ambiente. Companhia Ambiental do Estado de São Paulo - Cetesb. Padrões de qualidade do ar. Disponível em:< https://cetesb.sp.gov.br/ar/padroes-de-qualidade-doar/>. Acesso em: 06 jan. 2019.

SCHRAUFNAGEL, D.E. et al. Air Pollution and Noncommunicable Diseases. CHEST Journal. Pub. 9 nov. 2018. Disponível em< https://journal.chestnet.org/article/S0012-3692(18)32722-3/pdf>. Acessado em: 06 jan. 2019.

SOCIEDADE BRASILEIRA DE MEDICINA DE FAMÍLIA E COMUNIDADE - SBMFC. Classificação internacional de Atenção Primária (CIAP 2). Consultoria, supervisão e revisão técnica. Gustavo Diniz Ferreira Gusso. 2 ${ }^{\mathrm{a}}$ Ed. Florianópolis: Sociedade Brasileira de Medicina de família e Comunidade, 2009.

SZYSZKOWICZ, M. et al. Air pollution and emergency department visits for respiratory diseases: A multi-city case crossover study. Environmental Research, Elsevier, v.163, May 2018. Available from:< https://www.sciencedirect.com/science/article/pii/S0013935118300458>. Access on 02 Jan. 2019. https://doi.org/10.1016/i.envres.2018.01.043

WORLD HEALTH ORGANIZATION - WHO. Evolution of WHO air quality guidelines: past, present and future. Copenhagen: WHO Regional Office for Europe; 2017. Available from:< http://www.euro.who.int/_data/assets/pdf_file/0019/331660/Evolution-air-quality.pdf>. Access on: 02 jan. 2019.

Recebido em: 01/08/2018

Aceito para publicação em: 21/12/2018

$\begin{array}{llllll}\text { Caminhos de Geografia } & \text { Uberlândia-MG } & \text { v. 20, n. } 70 & \text { Junho/2019 } & \text { p. 398-417 Página } 417\end{array}$

